\title{
Pharmacokinetic Herb-Drug Interactions (Part 2): Drug Interactions Involving Popular Botanical Dietary Supplements and Their Clinical Relevance
}

Authors

Affiliations
Bill J. Gurley ${ }^{1}$, Espero Kim Fifer $^{2}$, Zoë Gardner ${ }^{2}$

${ }^{1}$ Department of Pharmaceutical Sciences, University of Arkansas for Medical Sciences, College of Pharmacy, Little Rock, AR, USA

${ }^{2}$ Department of Plant, Soil \& Insect Sciences, University of Massachusetts, Amherst, MA, USA
Key words

- herb-drug interaction

- plant secondary metabolites

- cytochrome P450 enzymes

- transferases

- ATP-binding cassette transporters

- solute carrier membrane transport proteins

- botanical dietary supplements

- black cohosh

- Echinacea

- garlic

- Ginkgo biloba

- ginseng

- goldenseal

- kava

- black pepper

- piperine

- Schisandra

- milk thistle

- St. John's wort

- methylenedioxyphenyl-

containing compounds

$\begin{array}{ll}\text { received } & \text { Dec. 22, 2011 } \\ \text { revised } & \text { February 6, 2012 } \\ \text { accepted } & \text { February 10, 2012 }\end{array}$

Bibliography

DOI http://dx.doi.org/

10.1055/s-0031-1298331

Published online May 7, 2012

Planta Med 2012; 78:

1490-1514 @ Georg Thieme

Verlag KG Stuttgart - New York .

ISSN 0032-0943

Correspondence

Dr. Bill Gurley

Department of Pharmaceutical

Sciences

UAMS, College of Pharmacy

4301 W. Markham St.

Little Rock, AR 72205

United States

Phone: + 15016866279

Fax: + 15015266510

gurleybillyj@uams.edu

\section{Abstract \\ $\nabla$}

In Part 2 of this review, a critical examination of the pertinent scientific literature is undertaken in order to assess the interaction risk that popular dietary supplements may pose when taken concomitantly with conventional medications. Botanicals most likely to produce clinically important herb-drug interactions are those whose phytochemicals act as mechanism-based inhibitors of cytochrome P450 enzyme activity (e.g., Hydrastis canadensis, Piper nigrum, Schisandra chinensis) or function as ligands for orphan nuclear receptors (e.g., Hypericum perforatum). In addition, several external factors unrelated to phytochemical pharmacology can augment the drug interaction potential of botanical supplements.

\section{Introduction}

$\nabla$

In Part 1 of this review, a discussion of the origins and mechanisms underlying herb-drug interactions was presented. In Part 2, a critical assessment of the available clinical evidence regarding herbdrug interaction potentials for several popular botanical supplements sold in the United States is provided. While the number of botanicals selected for review is not extensive, the approach taken to discern whether a botanical extract poses a risk for producing clinically significant herb-drug in-

\section{Nonstandard Abbreviations}

$\nabla$

ABC: $\quad$ ATP-binding cassette

AhR: aryl hydrocarbon receptor

AUC: area under the plasma concentrationtime curve

CAR: constitutive androstane receptor

CYP: $\quad$ cytochrome P450 enzyme

DSHEA: Dietary Supplement Health and Education Act

GMPs: good manufacturing practices

GST: glutathione S-transferase

MDR1: multidrug resistance protein 1

MDP: methylenedioxyphenyl

MDZ: midazolam

NADPH: nicotinamide adenine dinucleotide phosphate

OATP: organic anion transporting polypeptide

OTC: over-the-counter

P-gp: P-glycoprotein

PSM: plant secondary metabolite

PXR: pregnane xenobiotic receptor

SLC: $\quad$ solute carrier membrane transport protein

SULT: sulfotransferase

UGT: uridine diphosphate glycosyltransferase

UM: ultra-rapid metabolizer

XME: xenobiotic metabolizing enzyme

teractions can be extended to any supplement formulation. (For definitions of abbreviations regarding various drug metabolizing enzymes and transporters, see Part 1 of this review.)

\section{Black Cohosh}

$\checkmark$

Actaea racemosa L, (syn. Cimicifuga racemosa [L.] Nutt.; family Ranunculaceae) or black cohosh, is a perennial herb native to North America used traditionally by Native Americans for female repro- 


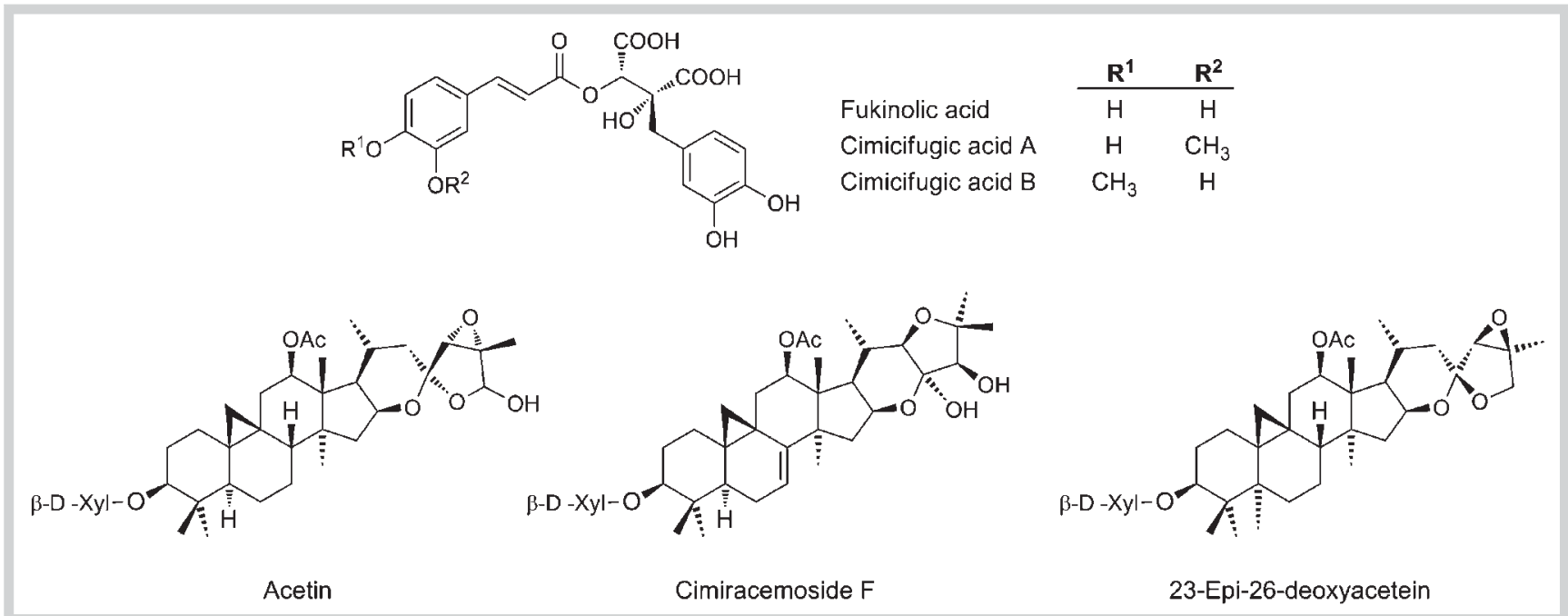

Fig. 1 Representative phytochemicals (triterpene glycosides, phenylpropanoids) present in black cohosh.

ductive system ailments and is now popular for the relief of menopausal symptoms such as hot flashes [1,2]. The purported ability of black cohosh to help alleviate climacteric symptoms, premenstrual syndrome, and osteoporosis has secured its ranking among the 10 top-selling supplements in the United States [3]. Spiroketal triterpene glycosides ( Fig. $\mathbf{1}$ ) are believed responsible for black cohosh's pharmacological activity even though they are not phytoestrogens $[4,5]$. As such, most commercial black cohosh products are chemically standardized to triterpene glycosides, with 23-epi-26-deoxyactein (also known as 27-deoxyactein) being the most abundant congener [6].

At present, black cohosh does not appear to be a potent modulator of human drug metabolism. In vitro studies found individual triterpene glycosides to be relatively weak inhibitors $\left(\mathrm{IC}_{50}\right.$ $>100 \mu \mathrm{M}$ ) of human CYP3A4 [7,8], while whole extracts elicited greater inhibition, a finding suggestive of synergy [7]. The inhibitory effects of whole black cohosh extracts may stem not from triterpene glycosides but rather fukinolic and cimicifugic acids. These compounds are potent $\left(\mathrm{IC}_{50}<13 \mu \mathrm{M}\right)$ inhibitors of CYP1A2, 2D6, 2C9, and 3A4 in vitro [8]; however, their quantities vary considerably among commercially available black cohosh products [9], a factor that can profoundly affect their inhibitory activity in vivo. In human liver microsomes, $\mathrm{IC}_{50}$ values for CYP2B6, 2C19, and $2 \mathrm{E} 1$ were approximately 50,30 , and $10 \mu \mathrm{g} / \mathrm{mL}$, respectively, for methanolic extracts of black cohosh [10]. However, when compared to standard regimens of clarithromycin (500 mg daily for 7 days) or rifampin (600 mg daily for 7 days), black cohosh supplementation (40-80 mg extract daily delivering 3-6 mg triterpene glycosides for 14 days) produced no demonstrable effects on digoxin and MDZ pharmacokinetics [11,12]. These findings suggest that black cohosh is not a potent modulator of human CYP3A4 or ABCB1 activity in vivo. Black cohosh supplementation also had no clinically significant effects on phenotypic measures of human CYP1A2, 2E1, or 2D6 activity [13]. When administered orally, black cohosh's principal triterpene glycoside, 23-epi-26deoxyactein, reaches the systemic circulation intact, albeit in very low concentrations ( $<10 \mathrm{ng} / \mathrm{mL}$ ) [6]. This apparent lack of biotransformation bolsters the idea that black cohosh triterpene glycosides are unlikely to be inhibitors of human XMEs in vivo. Black cohosh extracts incorporating DMSO as a cosolvent moder- ately inhibited ( 47\%) uptake of estrone-3-sulfate, a SLCO2B1 substrate, into human embryonic kidney cells stably expressing the transporter [14]. Whether this effect translates to the in vivo condition remains to be determined.

As with most commercially available botanical supplements, black cohosh products exhibit considerable variability in phytochemical profiles, and label claims for "standardized" marker compounds can deviate considerably from actual content [9]. Such variations can have considerable influence on how results of clinical studies evaluating black cohosh efficacy or its herbdrug interaction potential are interpreted. Nevertheless, based on the currently available data, standardized black cohosh supplements, when taken at recommended doses, pose little risk for herb-drug interactions.

Interaction risk: low.

\section{Echinacea spp.}

$\nabla$

Echinacea species (e.g., Echinacea purpurea [L.] Moench, E. angustifolia DC., E. pallida [Nutt.] Nutt.) of the family Asteraceae are North American perennials whose roots and aerial parts have been used traditionally for a variety of medicinal purposes [15, 16]. Echinacea formulations containing either root or whole plant extracts are marketed for their "immune stimulatory" properties and for prevention of the common cold $[15,16]$. Echinacea's popularity as an immune stimulator has placed it among the 10 topselling botanicals in the U.S. for many years. While evidence from in vitro and animal studies lend credence to Echinacea preparations as immunomodulators, clinical findings remain equivocal. (For reviews of clinical efficacy see references [15-19].) The three species most commonly encountered are chemically dissimilar. Both E. purpurea and E. angustifolia contain alkamides as their major lipophilic constituents, although of differing structural types ( Fig. 2). By contrast, the lipophilic fraction of E. pallida is characterized by polyacetylenes and is practically devoid of alkamides. These phytochemical dissimilarities also extend to their respective plant parts (i.e., roots vs. aerial parts). As PSMs, polyacetylenes and alkamides are natural pesticides that, when ingested in relatively high amounts, can be toxic. In low concentra- 


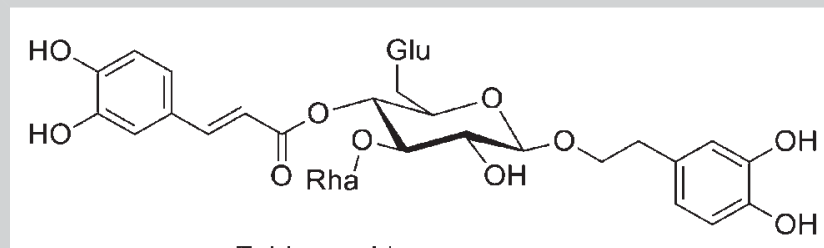

Echinacoside Glu $=$ Glucose, Rha $=$ Rhamnose<smiles>C/C=C/C=C/CC/C=C/C=C/C(=O)NCC(C)C</smiles>

$(2 E, 4 E, 8 Z, 10 Z)-N$-isobutyldodeca-2,4,8,10-tetraenamide<smiles>C#CC#CCCCC=CC(=O)NCC(C)C</smiles>

(E)-N-isobutylundeca-2-en-8,10-diynamide<smiles>O=C(/C=C/c1ccc(O)c(O)c1)OC1C[C@@](OC(=O)/C=C/c2ccc(O)c(O)c2)(C(=O)O)C[C@H](O)[C@H]1O</smiles>

Cynarin

(1,3-dicaffeoyl quinic acid)<smiles>O=C(O)/C=C/c1ccc(O)c(O)c1</smiles>

tions, however, alkamides appear to have beneficial effects [20]. Other PSMs like caffeic acid esters (e.g., cichoric acid, echinacoside), polysaccharides, and alkenes are also thought to contribute to echinacea's activity. Because commercially available Echinacea supplements often consist of extracts from various species and plant parts, considerable variation in phytochemical profile and content is common among products [16,21].

Permeability [22,23] and pharmacokinetic [24-26] studies indicate that several alkamides, but not caffeic acid conjugates, cross the intestinal mucosa reaching the systemic circulation intact. Following single doses of Echinacea alkamides $(\sim 11 \mathrm{mg})$ administered as tablets manufactured from ethanolic liquid extracts, plasma concentrations varied considerably with maximum plasma levels not exceeding $350 \mathrm{ng} / \mathrm{mL}$ [26]. Individual Echinacea alkamides are metabolized to varying degrees by several human CYPs, but when combined (as in an extract), metabolism is markedly reduced [27-29]. This appears to arise from (2E)- $N$-isobutylundeca2-ene-8,10-diynamide ( $\bullet$ Fig. 2 ), which contains a terminal alkyne and may act as a mechanism-based inhibitor [27]. A considerable number of in vitro studies have examined the XME and ABCB1 modulatory effects of echinacea extracts and individual PSMs [30-44]. A recent review of the bulk of these studies concluded that alkamides exhibit at least mild to moderate inhibiton of CYP3A4 in most of the model systems tested, with the magnitude dependent upon alkamide content [29]. This conclusion is strengthened by a recent animal study, in which standardized E. purpurea extracts reduced rat CYP3A mRNA levels by $40 \%$ [45]. Expression of CYP1A mRNA, however, was increased by
$80 \%$. Mild inhibitory effects on ABCB1- $[43,44]$ and SLCO2B1mediated [14] transport have also been demonstrated.

Very few prospective clinical studies examining the interaction potential of Echinacea supplements have been conducted in humans. Using the CYP3A probe midazolam, Gorski et al. concluded that 8 days of $E$. purpurea supplementation selectively modulated CYP3A activity in the intestine (inhibition) and liver (induction) of healthy volunteers [46]. The authors concluded that due to Echinacea's seemingly opposing effects on intestinal and hepatic CYP3A4, any interaction would depend upon the substrate's hepatic and intestinal extraction ratio. Mild inhibitory effects were observed for CYP1A2 and CYP2C9, while CYP2D6 was unaffected. In this instance, however, Echinacea's effect pales in comparison to those reported by these same investigators for known CYP3A4 inhibitors (e.g., clarithromycin) and inducers (rifampin) of midazolam metabolism $[47,48]$. It would appear that Echinacea's effect on CYP3A expression is modest at best, as neither standardized extracts nor purified alkamides upregulated CYP3A4 mRNA levels when exposed to HepG2 cells for 96 hours [41]. In contrast, rifampin exposure increased CYP3A4 mRNA expression by 3.8-fold. Using various phenotypic probe drug ratios to assess CYP1A2, CYP2D6, CYP2E1, and CYP3A4 activity, Gurley et al. found that healthy adults supplemented with E. purpurea for either 14 ( $800 \mathrm{mg}$ extract daily) [49] or 30 days (1500 mg extract daily) [50] produced no clinically significant changes in CYP phenotypes. More recently, Penzak et al. reported that 28 days of E. purpurea supplementation in healthy volunteers $(500 \mathrm{mg}$ three times daily) produced modest reductions in midazolam AUC 


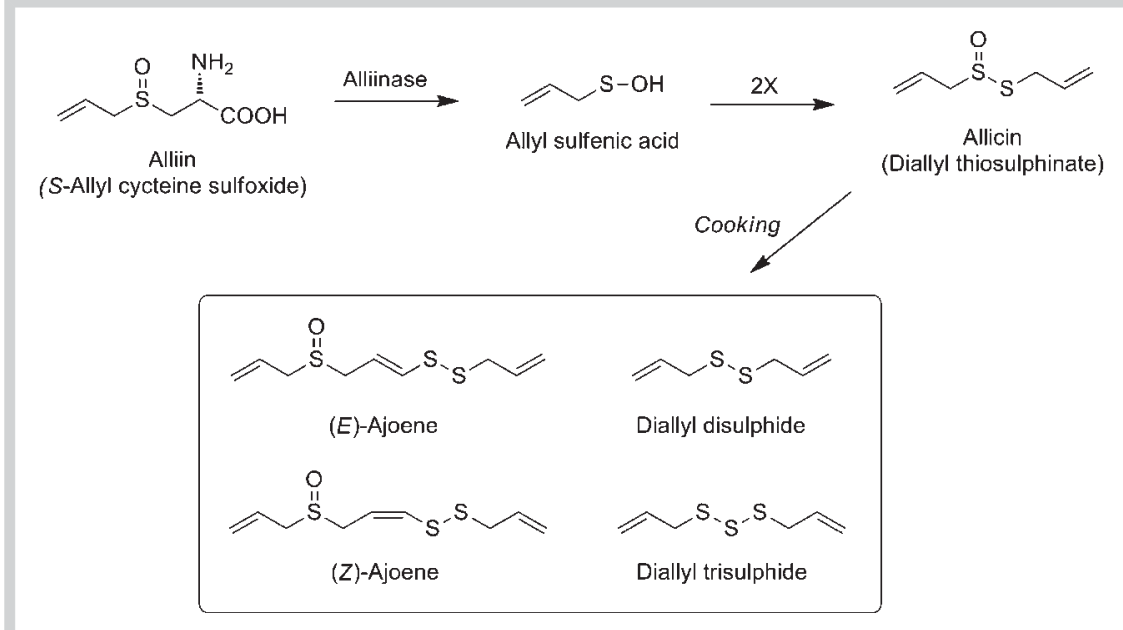

Fig. 3 Representative phytochemicals (sulfurcontaining compounds) present in garlic.

(27\% decrease), but had no significant effects on the pharmacokinetics of lopinavir and ritonavir (CYP3A4 substrates), or fexofenadine (a purported ABCB1 and SLCO substrate) [51]. This study, like that of Gorski et al., suggests that E. purpurea may have mild inductive effects on human CYP3A4 in vivo. However, when compared to rifampin's effects on the pharmacokinetics of CYP3A4 substrates $[12,48]$, any clinically important drug interactions with Echinacea seem remote.

To date, only two clinical studies have evaluated Echinacea's impact on drug transporters. Fourteen days of supplementation with a standardized, well-characterized E. purpurea product (800 mg extract daily) had no effect on digoxin (an ABCB1 substrate) pharmacokinetics in healthy volunteers [52]. By contrast, 7 days of rifampin ( $600 \mathrm{mg}$ daily) or clarithromycin (500 mg daily) produced marked reductions and increases, respectively, in digoxin AUC, a finding that underscores Echinacea's clinically insignificant effect on these transporters. In addition, the pharmacokinetics of fexofenadine, a nonspecific ABCB1 and SLCO substrate, were not impacted by 28 days of $E$. purpurea supplementation [51]. Taken together, these data render it unlikely that E. purpurea will produce clinically relevant interactions with coadministered drugs through ABC or SCLO modulation.

Based on the collected evidence to date, it appears that dietary supplements formulated with standardized Echinacea extracts when ingested per label recommendations - are not likely to yield alkamide concentrations sufficient enough to dramatically modulate human CYP, ABC, and SLCO isoforms in vivo. Therefore, Echinacea supplements pose minimal risks for interacting with most conventional medications, an opinion concordant with that of other recent reviews $[29,53]$.

Interaction risk: low.

\section{Garlic}

\section{$\nabla$}

Members of the family Alliaceae have been an important part of the human diet for thousands of years. Allium species, such as garlic (Allium sativum L.) and onions (Allium cepa L.), are a rich source of sulfur-containing compounds, many of which are volatile and give rise to the characteristic flavor and aroma of these species. Fresh garlic has little smell but tissue damage by cutting, crushing, or biting results in alliin (2-propenyl-L-cysteine sulfoxide) ( Fig. 3 ) being cleaved by the enzyme alliinase resulting in the formation of allicin (diallyl thiosulfinate), which gives crushed garlic its characteristic smell. Because allicin is very unstable to heat, cooking results in its degradation to a number of organosulfur compounds including diallylsulfides and ajoenes [54] ( Fig. 3). Bad breath, which follows the ingestion of garlic products, is due to a range of sulfide compounds that appear in the systemic circulation and expired air.

Garlic is reputed to have benefits for protection against cardiovascular diseases, cancer, microbial infections, and vampires! Although there is some evidence for the first two effects, the rest are largely the result of speculation and folklore [54]. The putative anti-hypercholesterolemic effect of garlic supplements makes them one of the most widely used botanical supplements in the United States. Their efficacy, however, remains in doubt due to conflicting results from numerous published clinical trials [5558]. This is probably a function of the type of product used, its quality, and poor characterization of the phytochemical agent(s) responsible for garlic's lipid lowering effect.

Three general categories of garlic supplements are available commercially (garlic oil, dehydrated garlic powder, and aged garlic extract) each with their own unique composition of purported bioactive components [59-61]. Within these products a plethora of organosulfur compounds, steroid saponins, and other phytochemicals have been identified [54,59-62]. Of these, the oil-soluble organosulfur compounds including allyl thiosulfinates (e.g., allicin), alkyl sulfides (e.g., diallyl sulfide), vinyldithiins, and ajoene have received the most attention ( $\bullet$ Fig.3). Allicin has long been touted as the agent responsible for garlic's lipid lowering effects, yet the compound is unstable in the gastrointestinal tract, is not bioavailable, and is rarely found in commercial products [59-61]. Allicin's degradation products, diallyl sulfide, diallyl disulfide, diallyl trisulfide, dithiin, and ajoene, may contribute to the lowering of serum cholesterol levels; however, many products, particularly those containing garlic oil, have relatively poor efficacy $[63,64]$. In addition, many in vivo studies indicate that garlic oil and individual alkyl sulfides, most notably diallyl sulfide and allylmethylsulfide, inhibit murine and human CYP2E1 [6568]. This is likely a result of the CYP2E1-catalyzed biotransformation of diallyl sulfide to diallyl sulfoxide and diallyl sulfone, in which the latter is a mechanism-based inhibitor of the enzyme $[66,69]$. Despite inhibition of human CYP2E1 in vitro, few interactions involving garlic products and CYP2E1 substrates have been reported, a consequence that probably reflects the paucity 
of drugs metabolized by this enzyme. Conversely, prolonged administration of diallyl sulfide and diallyl disulfide induced other hepatic and intestinal murine CYP subfamilies (e.g., CYP1A, CYP2B, CYP3A), in addition to various transferases (e.g., GSTs, UGTs) $[65,70-76]$ through activation of CAR and Nrf2 nuclear receptors [77].

The ability of garlic to inhibit other human CYP isoforms also appears dependent upon product type and composition. In vitro assessments of allicin, fresh garlic, or commercially prepared supplements (e.g., garlic oil and garlic powder) either found no effect $[32,78]$ or modest inhibition $(<50 \%)$ of human CYP2C9, CYP2C19, and CYP3A4 isoforms [79,80]. A freeze-dried garlic supplement, however, produced significant inhibition of CYP3A4 in vitro (>95\%) [80]. Because the chemistry of garlic is complex and because different types of processing can significantly alter its phytochemical composition, lyophilization may stabilize those organosulfur compounds capable of inhibiting CYP3A4. Aged garlic extracts (AGE), on the other hand, do not appear to inhibit any of the major CYP isoforms present in human liver microsomes [81]. This may stem from a dearth of oil-soluble organosulfur compounds in AGE and a preponderance of water-soluble components (e.g., S-allyl-L-cysteine, saponins) [59]. The shift from oil- to water-soluble ingredients arises from the aging process and subsequent aqueous extraction, which makes AGE distinct from the other types of garlic products.

Based upon in vitro and murine in vivo findings, garlic's effects on transporter activity also appear dependent upon the hydrophilicity of specific organosulfur compounds. The preponderance of in vitro data regarding $\mathrm{ABC}$ isoforms implies that garlic's oil-soluble organosulfur compounds are not potent inhibitors of the efflux transporter ABCB1 [80,82-85] but may, however, induce ABCC2 expression [85]. Interestingly, lipophilic compounds (e.g., diallyl sulfide, diallyl disulfide) increased $A B C B 1$ efflux through rat ileum but not through Caco-2 cell monolayers [86]. When exposed to both Caco- 2 cell monolayers and the rat intestine at high concentrations $(\sim 12 \mu \mathrm{g} / \mathrm{mL})$, water-soluble compounds in AGE (e. g., $S$-allyl- $L$-cysteine) induced the activity of $A B C B 1, A B C C 2$, and SLCO transporters $[86,87]$. In a HepG2 cell line, however, ABCC2 activity was reduced, suggesting that AGE-mediated regulation of $A B C C 2$ proteins in the liver is different from that in the intestine [88]. Tissue-specific regulation of $A B C C 2$ activity has also been observed for other xenobiotics [89], and this may only add to the difficulties of predicting garlic-drug interactions.

A modest number of prospective human studies have investigated the drug interaction potential of garlic supplements or purified garlic organosulfur compounds [90-102]. Owing to the variety of products evaluated and diverse dosages of garlic phytochemicals administered, results have been mixed. A number of drugs, whose biotransformation pathways run the gamut of human XMEs, have been assessed (e.g., acetaminophen, alprazolam caffeine, chlorzoxazone, cyclosporine, debrisoquine docetaxel dextromethorphan, midazolam, omeprazole, ritonavir, saquinavir, warfarin), yet the evidence implies that only substrates of CYP2E1 are significantly affected $[90,92,98]$. The first prospective study by Gwilt et al. found that daily administration of aged garlic extract ( $\sim 19 \mathrm{mg} S$-allyl- $L$-cysteine) produced no significant effects on the pharmacokinetics of acetaminophen, a putative CYP2E1 substrate [91]. Later, Loizou and Crocker observed that administration of diallyl sulfide $(\sim 0.2 \mathrm{mg} / \mathrm{kg})$ to healthy volunteers reduced plasma 6-hydroxychlorzoxazone/chlorzoxazone ratios (a phenotypic measure of CYP2E1 activity) by an average of $31 \%$ [92]. This finding confirmed in humans what had been previously observed in murine models that lipophilic, and not hydrophilic, organosulfur compounds were CYP2E1 inhibitors. Subsequent studies confirmed that prolonged garlic oil supplementation ( $500 \mathrm{mg}$, three times daily for 28 days) inhibited human CYP2E1 activity in both young [90] and elderly adults [98] by almost $40 \%$ and $25 \%$, respectively; however, no modulatory effects were noted for CYP1A2, CYP2D6, or CYP3A4. In contrast, 21 days of twice daily supplementation with garlic powder $(\sim 9 \mathrm{mg}$ allicin and $23 \mathrm{mg}$ alliin) reduced by $50 \%$ the mean AUC, 8-hour trough concentrations, and mean maximum plasma concentrations $\left(C_{\max }\right)$ of the protease inhibitor saquinavir [93]. The authors concluded that the garlic powder supplement might have induced intestinal CYP3A4 and/or P-gp, since saquinavir is a substrate for both proteins. A similar, although less dramatic, effect on ritonavir AUC, was observed after a four-day course of garlic extract (5 mg, twice daily) [94]. Subsequent studies examining the prolonged effects of garlic supplementation on other CYP3A4 substrates, however, failed to note any significant changes [9597]. Nor have any clinically important garlic-mediated interactions been reported for warfarin, a recognized substrate for CYP2C9 and 3A4 [100,101]. However, large doses of the organosulfur compound allicin ( $150 \mathrm{mg}$ daily) did reduce the metabolism of omeprazole by inhibiting CYP2C19 activity in individuals both homozygous and heterozygous for the CYP2C19*1 allele, but not for those homozygous for CYP2C19*2 [102]. Interestingly, the CYP3A4-mediated omeprazole sulfone pathway was not affected. Reductions in saquinavir and ritonavir concentrations noted in early studies appear attributable to garlic-mediated upregulation of intestinal $\mathrm{ABCB} 1$ or $\mathrm{ABCC} 2$ activity as was demonstrated in several recent in vitro investigations [84-89]. The extent to which garlic supplementation affects human ABC and SLCO substrates in vivo was recently addressed in healthy volunteers receiving a standardized garlic extract for 21 days [103]. A 31\% increase in the duodenal expression of human $A B C B 1$ correlated with a modest reduction in saquinavir AUC while no significant effects were noted in the pharmacokinetic parameters of simvastatin (a CYP3A4 substrate) or pravastatin (an SLCO1B1 substrate).

Taken together the accumulated findings imply that most commercially available garlic supplements pose only a limited risk for producing clinically important herb-drug interactions. Presently, only human CYP2E1 appears to be inhibited by garlic oil products, but because only a few drugs are substrates of CYP2E1 and most of those have fairly broad therapeutic indicies, this interaction is not cause for great concern. On the other hand, prolonged consumption of garlic extract appears to modestly induce the human efflux transporter ABCB1. Accordingly, prolonged exposure to concentrated garlic extracts may reduce the efficacy of drugs whose disposition is strongly dependent on ABCB1. Interaction risk: low.

\section{Ginkgo biloba}

Termed living fossils, ginkgo trees (family Ginkgoaceae) have existed since the early Jurassic period 150 million years ago. The lone species that avoided extinction (Ginkgo biloba L.) is now cultivated in Asia, Europe, North America, New Zealand, and Argentina. Ginkgo is a popular ornamental tree recognizable by its unusual fan-shaped leaves that turn bright yellow in autumn. In Asia, the tree has long been held sacred for its therapeutic value. Today, dosage forms incorporating $G$. biloba leaf extracts are used throughout the world for treatment of insufficient blood flow, 


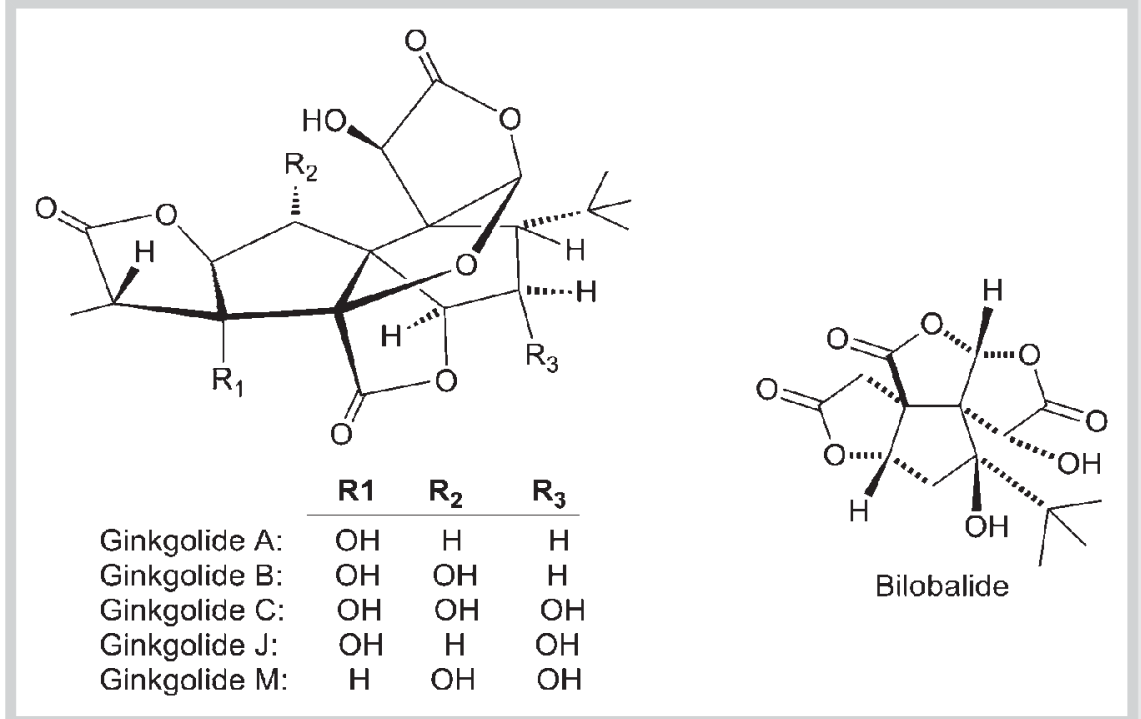

Fig. 4 Representative phytochemicals (terpene lactones, flavonoid glycosides) present in Ginkgo biloba.

memory deficits, cognitive disorders, Alzheimer's disease, depression, vertigo, tinnitus, and intermittent claudication [104]. Ginkgo's popularity has made it one of the most intensely studied botanicals in the world. Currently more than 2500 articles related to $G$. biloba have been published in the medical literature.

Clinical trials on the efficacy of $G$. biloba extracts are numerous and controversial [105-109]. Much of the research has centered on products formulated with EGb 761, an extract produced by the German company Schwabe. EGb 761 is a standardized, concentrated extract containing $24 \%$ flavonoid glycosides (e.g., quercetin, kaempferol, isorhamnetin), 6\% terpene lactones $(3.1 \%$ ginkgolides $\mathrm{A}, \mathrm{B}, \mathrm{C}$, and $\mathrm{J}$ and $2.9 \%$ bilobalide), $5-10 \%$ organic acids, and other constituents [104]. Several other companies produce ginkgo extracts with similar chemical profiles. Terpene lactones are unique to $G$. biloba and include the ginkgolides, a group of diterpene trilactones (e.g., ginkgolide A, B, C, J, M), and bilobalide, a sesquiterpene lactone ( Fig. 4). G. biloba flavonoids occur principally as glycoside derivatives, with quercetin, kaempferol, and isorhamnetin being the most prevalent. Other PSMs present in G. biloba that may have allergenic, immunotoxic, and other undesirable properties (e.g., ginkgetin, amentoflavone, ginkgolic acids, ginkgotoxin, and others) are typically removed during processing [104].

Discrepancies among clinical studies regarding efficacy may be traced to significant interproduct variability in phytochemical content and biopharmaceutical characteristics of ginkgo extract dosage forms (e.g., disintegration, dissolution, bioavailability) $[110,111]$. These same discrepancies may also underly the confusion surrounding the herb-drug interaction potential of G. biloba. Depending upon which experimental model is utilized, different interpretations of ginkgo's drug interaction capabilities emerge. In many in vitro experimental systems, ginkgo extracts $[14,33$, $35,38,112-119]$, as well as individual terpene lactones [110, $111,115-120]$ and flavonoid glycosides [14,115-123] have been shown to inhibit various XMEs and transporters, although in most instances IC $_{50}$ values were well in excess of $20 \mu \mathrm{M}$. Aglycones of quercetin, kaempferol, and isorhamnetin seem to have the greatest inhibitory capacity [116,119-126], while ginkgolides and bilobalide exhibit the least and in many cases, none at all $[79,116-119,123,124,127]$. In contrast, ginkgo extracts and individual terpene lactones appear capable of inducing the expression of several CYP, UGT, and ABC isoforms in rat [128-130] and human primary hepatocytes $[113,114,130,131]$ as well as human mammary epithelial cells [132]. Cell-based reporter assays in HepG2 [121,131] and LS180 [133] and other cell lines $[132,134]$ revealed that ginkolides A and B are activators of PXR, whereas quercetin and kaempferol activated PXR, CAR, and AhR. Bilobalide exerted no effects on nuclear receptors in these assays. The discovery that specific ginkgolides and flavonoids are ligands for several xenobiotic receptors provides an explanation for a host of recent in vivo studies in which prolonged administration of $G$. biloba extracts to rats, often in high doses, not only induced a multitude of XMEs [135-140] but reduced efficacy for several drug substrates: nicardipine [141], tolbutamide [142], phenobarbital [143], propranolol [144], cyclosporine [145], and theophylline [146]. Concomitant administration of G. biloba also enhanced the hepatotoxicity of acetaminophen via CYP3A induction [147]. However, several of these in vivo studies contradicted cell-based reporter assay findings when bilobalide was implicated as an XME activator [148-150].

Evidence from in vitro and animal investigations clearly points to G. biloba extracts and their constituents as inducers of XME and transporter activity. These findings have led investigators to warn of significant drug interactions with G. biloba. Clinical evidence substantiating these claims, however, is not as compelling. To date, 29 prospective clinical trials assessing the effect of $G$. biloba supplementation on the pharmacokinetics of a variety of drugs, including several specific CYP probes, have been published [90,98, 139, 151-176]. Twenty-nine different drugs whose metabolism or transport is mediated by various CYP isoforms (e.g., CYP1A2, CYP2B6, CYP2C9, CYP2C19, CYP2D6, CYP2E1, CYP3A4) or transporters (e.g., ABCB1, SLCO1B1, SLCO2B1) were evaluated. The drugs included aspirin [167], alprazolam [161], antipyrine [152], bupropion [174], caffeine [90,98, 154], chlorzoxazone [90, 98, 154], cilostazol [162], clopidogrel [162], dapsone [154], debrisoquine [90,98,154], dextromethorphan [157], diazepam [175], diclofenac [163], digoxin [156], donepezil [159], endogenous steroids [139,161], fexofenadine [170], flurbiprofen [164], lopinavir [170], mephenytoin [154], metformin [169], midazolam [90,98, $166,170]$, nifedipine $[153,158]$, omeprazole [151], talinolol $[172,173]$, ticlopidine $[165,176]$, tolbutamide $[163,166]$, vorico- 


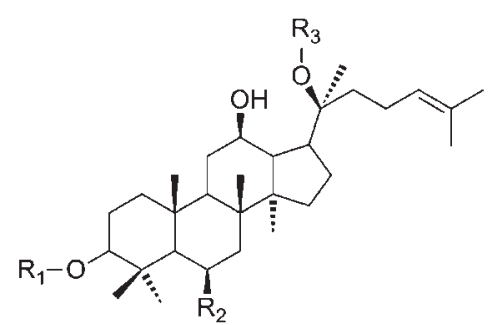

\begin{tabular}{llll} 
Compound & $\mathbf{R}_{\mathbf{1}}$ & $\mathbf{R}_{\mathbf{2}}$ & $\mathbf{R}_{\mathbf{3}}$ \\
\hline
\end{tabular}

\begin{tabular}{|c|c|c|c|}
\hline \multicolumn{4}{|c|}{ Protopanaxadiol derivatives } \\
\hline $\mathrm{Rb}_{1}$ & $-\mathrm{Glc}^{2}-{ }^{1} \mathrm{Glc}$ & $-\mathrm{H}$ & $-\mathrm{Glc}^{6}-{ }^{1} \mathrm{Glc}$ \\
\hline $\mathrm{Rb}_{2}$ & $-\mathrm{Glc}^{2}-{ }^{1} \mathrm{Glc}$ & $-H$ & $-G_{c} c_{-1}^{-1}$ Arap \\
\hline $\mathrm{Rc}$ & $-G c^{2}-1 G \mid c$ & $-H$ & $-\mathrm{Glc}^{6}-{ }^{1} \mathrm{Araf}$ \\
\hline $\mathrm{Rd}$ & $-\mathrm{Glc}^{2}-{ }^{1} \mathrm{Glc}$ & $-H$ & $-G \mid c$ \\
\hline $\mathrm{Rg}_{3}$ & $-G^{2}{ }^{2}-{ }^{1} G \mid c$ & $-H$ & $-H$ \\
\hline $\mathrm{Rh}_{2}$ & $-G l c$ & $-\mathrm{H}$ & $-H$ \\
\hline Compd K (C-K) & $-H$ & $-H$ & $-G l c$ \\
\hline 20(S)-protopanaxadiol $(\mathrm{Ppd})$ & $-H$ & $-H$ & $-\mathrm{H}$ \\
\hline
\end{tabular}

$\begin{array}{cccc}\begin{array}{c}\text { Protopanaxatriol derivatives } \\ \mathrm{Re}\end{array} & -\mathrm{H} & -\mathrm{O}-\mathrm{Glc}^{2}-{ }^{1} \mathrm{Rha} & -\mathrm{Glc} \\ \mathrm{Rg}{ }_{1} & -\mathrm{H} & -\mathrm{O}-\mathrm{Glc} & -\mathrm{Glc} \\ \mathrm{Rg}_{2} & -\mathrm{H} & -\mathrm{O}-\mathrm{Glc}^{2}-{ }^{1} \mathrm{Rha} & -\mathrm{H} \\ \mathrm{Rh}_{1} & -\mathrm{H} & -\mathrm{OGlc} & -\mathrm{H} \\ \mathrm{Rf} & -\mathrm{O}-\mathrm{Glc}^{2}-{ }^{-} \mathrm{Glc} & -\mathrm{H} & -\mathrm{H} \\ 2 \mathrm{~S}(\mathrm{~S}) \text {-protopanaxatriol }(\mathrm{Ppt}) & -\mathrm{H} & -\mathrm{OH} & -\mathrm{H}\end{array}$

Fig. 5 Representative phytochemicals (ginsenosides) present in the Panax species.

nazole [171], and warfarin [155,160,168]. The majority of these studies followed a G. biloba supplementation regimen of $240 \mathrm{mg}$ leaf extract twice daily from as few as 3 to as many as 90 days, while others utilized smaller doses. In addition, most utilized products containing the standardized EGb 761 extract. Of the 29 studies (many of which evaluated more than one drug), 23 observed no significant effects of G. biloba on drug disposition, 5 observed a modest inhibitory effect $[153,154,166,172,173]$, and 3 demonstrated evidence of CYP3A4 [168], CYP2C9 [164], and CYP2C19 [151] induction. Moreover, when compared to FDA guidelines on drug interaction criteria $[177,178]$, those few studies demonstrating a modulatory effect of G. biloba on drug disposition do not appear to be clinically important.

Discrepancies in G. biloba's effect on rat and human XMEs in vivo do not appear to reflect species differences in PXR activation $[129,179]$, but rather seem to be dose related $[136,139]$. Most rat studies administered G. biloba extracts at $100 \mathrm{mg} / \mathrm{kg} / \mathrm{day}$, a dose comparable to $1300 \mathrm{mg} /$ day or greater in humans; however, most human studies incorporated doses of $240 \mathrm{mg} /$ day or less.

Additionally, several studies have assessed the pharmacokinetics of ginkgolides and bilobalide in human volunteers. Following $240 \mathrm{mg}$ doses of standardized $\mathrm{G}$. biloba extracts, $C_{\max }$ values for ginkgolides and bilobalide rarely exceeded $40 \mathrm{ng} / \mathrm{mL}$ [180-182], concentrations well below the $4000 \mathrm{ng} / \mathrm{mL}$ at which ginkgolides $A$ and $B$ activated PXR in vitro [133]. It is possible that concentrations exceeding $40 \mathrm{ng} / \mathrm{mL}$ may be achieved within intestinal enterocytes, but this depends upon disintegration and dissolution profiles of individual dosage forms (characteristics that can vary considerably between brands $[183,184])$, as well as the permeability of individual terpene lactones or flavonol glycosides. In Caco-2 and MDR1-MDCK cell monolayers, ginkgolides and bilobalide exhibited low absorptive permeability and high efflux [185]; two conditions that would further preclude their exposure to enteric XMEs.

In summary, dosage forms containing standardized G. biloba extracts, when administered at doses of $240 \mathrm{mg} /$ day or less, do not pose a risk for clinically relevant herb-drug interactions. However, daily doses exceeding $240 \mathrm{mg}$ /day may increase prospects for interactions.

Interaction risk: low, at doses $240 \mathrm{mg} /$ day or lower.

\section{Ginseng spp.}

$\nabla$

Of the five major Panax species (family Araliaceae) worldwide, Asian ginseng (Panax ginseng C.A. Meyer) and American ginseng (Panax quinquefolius L.) are the most widely used and extensively studied. P. ginseng root has an almost 2000-year history of use in traditional Chinese medicine (TCM) as an adaptogen (a plant that increases resistance to stress and fatigue) and a restorative tonic. Today, ginseng root, either as a TCM or dietary supplement, is one of the most popular herbs in the world; used to improve libido and sexual performance, prevent cancer, regulate blood sugar, lower blood pressure, improve cognition, fight fatigue, and boost immunity [186]. With the possible exception of its mild hypoglycemic effect, ginseng's efficacy remains questionable, as many clinical trials have produced confounding results [187-189]. Ambiguity in clinical findings may be linked to differences in the ginsosenoside content of products evaluated.

Ginsenosides, a group of triterpene glycosides (steroidal saponins), are unique to Panax species. More than 40 ginsenosides have been identified in the roots of $P$. ginseng and $P$. quinquefolius. Ginsenoside nomenclature employs the designation $\mathrm{Rx}$, where $\mathrm{x}$ represents the retention factor (Rf) value from the sequence of spots (from bottom to top) on thin-layer chromatography plates. Ginsenosides exhibit considerable structural variation. They differ from one another by the type, number, and site of attachment of sugar moieties. The two major subtypes of ginsenosides - protopanaxadiol and protopanaxatriol - are classifed according to the arrangement and number of sugar (glucose, rhamnose, xylose, and arabinose) residues on the steroidal skeleton [190]. $\mathrm{Rb} 1, \mathrm{Rb} 2, \mathrm{Rc}$, and Rd are examples of protopanaxadiol ginsenosides, while Re, Rf, Rg1, and Rg2 are examples of protopanaxatriols ( Fig. 5). P. ginseng and P. quinquefolius differ significantly in type and proportion of ginsenosides, with $P$. ginseng having a high $\operatorname{Rg} 1:$ Rb1 ratio and $P$. quinquefolius a low $\operatorname{Rg} 1: \operatorname{Rb} 1$ ratio [191]. Such distinctions may account for differences in purported efficacy between the two species. Ginseng root extracts are often standardized to contain a particular percentage $(\sim 4 \%)$ and ratio of ginsenosides. When ingested, ginsenosides undergo partial hydrolytic deglycosylation in the stomach and are further deglycosylated in the large intestine through enzymatic glucosidase activity of gut microflora [190,192-194]. It is these metabolites (e.g., compound K, $\odot$ Fig. 5) that ultimately reach the systemic circulation and are alleged to have pharmacologic activity [192,194-196].

From a drug interaction perspective, clinical and nonclinical evidence regarding ginseng extracts and their effects on XMEs and transporters is particularly confusing. This confusion stems from an assortment of variables affecting ginsenoside disposition. 


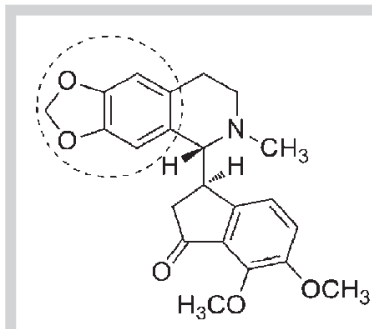

$(-)-\beta$-Hydrastine
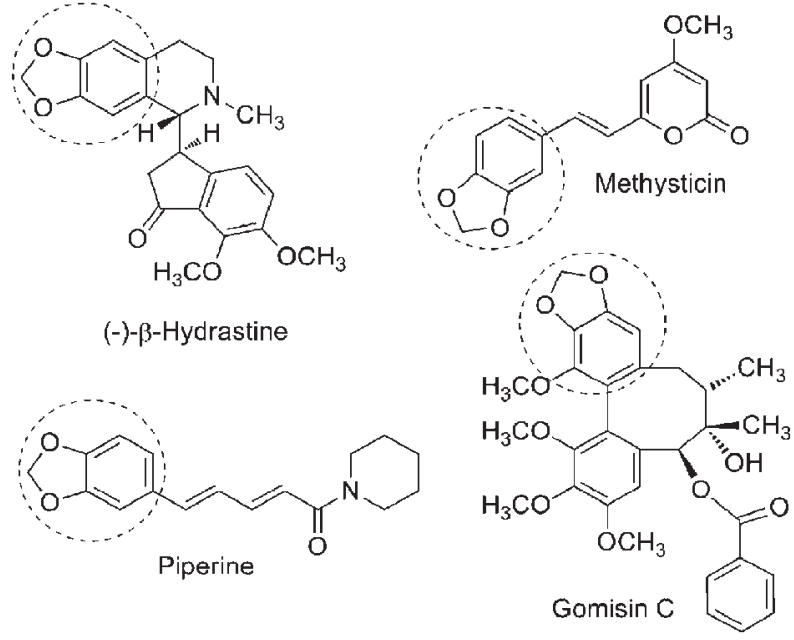

Fig. 6 Representative methylenedioxyphenyl-containing phytochemicals (broken circle $=$ methylenedioxyphenyl moiety).

These include, but are not limited to, variability in ginsenoside type and content $[190,191]$, degree of preabsorptive deglycosylation [192-195], poor membrane permeability [197], interindividual differences in gut microflora [192-194], and enteric efflux by $A B C$ transporters $[198,199]$. It is now clear that highly polar, extensively glycosylated ginsenosides (e.g., Rb1, Rb3, Rg3, Re, Rg1, Rg2) are relatively weak modulators of human XMEs and transporters [37, 120,200-207]. Ginsenoside concentrations necessary to inhibit most CYPs and transporters in vitro are not only high $(>50 \mu \mathrm{M})$, but are not likely to be realized in vivo, especially if normal dosing recommendations of ginseng products are followed $[37,120,127,200-207]$. This also holds true for the even higher ginsenoside concentrations $(>100 \mu \mathrm{M})$ required for inducing CYP1A1 [208], CYP2C9, and CYP3A4 [200] activity in human liver cells and microsomes. However, the products of ginsenoside hydrolysis (e.g., deglycosylated metabolites) have been shown to competitively inhibit a variety of CYPs and transporters, oftentimes at concentrations well below $20 \mu \mathrm{M}$ [203-208].

Only a limited number of animal studies have examined the effects of orally administered ginseng extracts ( $>30 \mathrm{mg} / \mathrm{kg}$ ) on drug disposition. From these, it appears that $P$. ginseng or $P$. quinquefolius either mildly induce [209-211] or have no significant effects [212-214] on rat XMEs and ABCB1 activity in vivo. Substantially more prospective human trials have investigated the effects of $P$. ginseng and $P$. quinquefolius supplementation on human drug disposition, with the CYP2C9 substrate, warfarin, being examined the most. Like the murine studies, clinical results fall into two catgories: no effect $[90,98,215-219]$ or mild induction [217,220-222].

Concerns regarding possible ginseng-drug interactions first surfaced when two case reports speculated that ginseng reduced warfarin anticoagulation [223,224]. As single case reports cannot establish causation, a prospective clinical trial by Yuan et al. demonstrated that international normalized ratios (INR, a measure of anticoagulation), peak plasma warfarin levels, and warfarin AUCs were reduced by P. quinquefolius in healthy volunteers, and these effects reached statistical significance [221]. Subsequent clinical trials with $P$. ginseng, however, have failed to observe any influence on warfarin pharmacokinetics $[216,222]$ or pharmacody- namics [216, 218, 222]. Such discrepancies may reflect the disparity in ginsenoside profiles between $P$. ginseng and P. quinquefolius; however, several methodological concerns have been raised about the Yuan et al. study including it being underpowered, that inadequate sampling was used to determine AUC, and a non-stereoselective assay was used to measure warfarin enantiomers [222]. Therefore, it appears that whatever effect(s) P. quinquefolius extracts might have on human CYP2C9 activity, their magnitude does not reach clinical significance. As a result, the available evidence that links ginseng supplementation to potentially harmful drug interactions remains unconvincing. Interaction risk: low.

\section{Methylenedioxyphenyl-Containing Phytochemicals}

$\nabla$

The plant kingdom is replete with species that harbor phytochemicals whose structures contain methylenedioxyphenyl (MDP) moieties ( Fig. 6). Popular botanical supplements known to contain substantial quantities of MDP-PSMs include goldenseal (Hydrastis canadensis), kava kava (Piper methysticum), black pepper (Piper nigrum), and Schisandra spp. In these species, MDP-containing PSMs (MDP-PSMs) often function as insecticides [225], but when consumed by humans they can act as mechanism-based inhibitors of CYPs [226,227]. This type of inhibition is thought to arise from CYP-dependent oxidation of the methylenedioxy carbon to a carbene that subsequently interacts with CYP heme iron to produce a stable heme-adduct, termed a metabolic-intermediate (MI) complex [227]. It is through the formation of MI complexes that CYP isoforms are inactivated by MDP-PSMs [227,228]. Because MDP-PSMs can function as mechanism-based CYP inhibitors, they pose significant risks for herb-drug interactions.

Prolonged administration of MDP-containing compounds has also been shown to induce CYP1A and CYP2B expression in several animal species [227-229]. Induction of CYPs by MDP-PSMs may be mediated by AhR or through mechanisms that promote protein stabilization $[228,229]$. Whether CYP inhibition or induction predominates in vivo may depend upon the length and bulk of MDP side chains as well as the individual CYP isoform examined [230]. MDPs with long bulky side chains appear to be more potent inhibitors of CYP1A2, CYP2C9, CYP2D6, and CYP3A4, whereas CYP2B6 and CYP2C19 are not inactivated [230].

\section{Goldenseal}

Extracts of goldenseal root (Hydrastis canadensis L.; family Ranunculaceae), a perennial herb indigenous to eastern North America, are often taken as an antimicrobial to prevent common colds and upper respiratory tract infections. Often formulated with Echinacea species, goldenseal ranks among the top-selling botanicals in the United States.

Goldenseal's medicinal properties are attributed to several isoquinoline alkaloids, of which berberine and hydrastine ( $\bullet$ Fig. 7 ) are the most prevalent. Both berberine and hydrastine are MDP-PSMs that inhibit various CYP isoforms in vitro $[10,30,31,34,36,37$, 231]. Using fluorometric microtiter plate assays, Budzinski et al. first noted that commercial extracts of Hydrastis canadensis were potent in vitro inhibitors of CYP3A4 [30]. Follow-up investigations by these authors found that goldenseal reduced CYP3A-mediated conversion of testosterone to its $6 \beta$-hydroxy metabolite by $88 \%$ [31]. Chatterjee and Franklin later confirmed the inhibition of testosterone $6 \beta$-hydroxylation by goldenseal extracts and ex- 


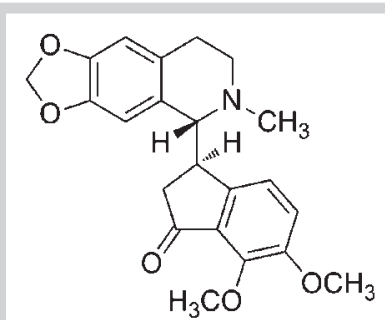

$(-)-\beta$-Hydrastine
Berberine

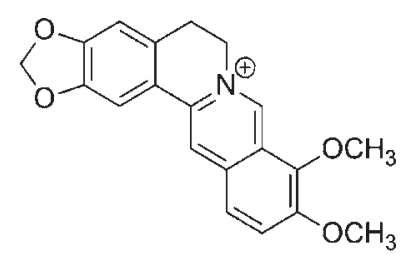

Fig. 7 Representative phytochemicals (isoquinoline alkaloids) present in goldenseal.

tended their findings to include individual isoquinoline alkaloids [231]. They demonstrated that hydrastine was a more potent inhibitor of CYP3A4 $\left(\mathrm{IC}_{50}=25 \mu \mathrm{M}\right)$ than berberine $\left(\mathrm{IC}_{50}=400 \mu \mathrm{M}\right)$. It is seldom that prospective clinical studies corroborate in vitrobased predictions of CYP-mediated herb-drug interactions; however, goldenseal appears to be an exception. Using phenotypic measures of CYP activity, Gurley et al. first observed that goldenseal supplementation significantly inhibited CYP2D6 and CYP3A4 in healthy volunteers [13]. In subsequent investigations with the CYP3A4 probe midazolam, Gurley et al. further demonstrated that 14 days of goldenseal supplementation $(\sim 209 \mathrm{mg}$ isoquinoline alklaoids daily) significantly increased midazolam AUC, $C_{\max }$, and elimination half-life, and that the effects were proportional to those produced by the well-recognized, mechanism-based inhibitor clarithromycin (1000 mg daily) [232]. In addition, goldenseal's inhibition of human CYP2D6 in vivo was confirmed with other commercially available supplement brands [49]. Interestingly, another prospective study evaluating the influence of goldenseal supplementation on the pharmacokinetics of indinavir (a protease inhibitor and CYP3A4 substrate) failed to register any significant effects [233]. This discrepancy may stem from the relatively high oral bioavailability of indinavir, which renders it a less effective probe for assessing herb-mediated changes in CYP3A activity. Thus, goldenseal may have its greatest impact on those CYP3A substrates exhibiting high intestinal metabolism and low oral bioavailability.

In China, berberine (an OTC remedy for diarrhea of bacterial origin) has also been shown to significantly increase the AUC, $C_{\max }$, and trough concentrations of the immunosuppressive drug cyclosporine [234,235]. Since cyclosporine is both a CYP3A4 and ABCB1 substrate, the activity of both of these proteins could conceivably be affected by hydrastine and berberine. There is convincing in vitro and animal evidence that berberine is a substrate for certain $A B C$ isoforms [236-240], and thus, it may compete with other $A B C$ substrates for efflux across intestinal and canalicular membranes. Recent clinical evidence, however, indicates that goldenseal's effect on digoxin (an ABCB1 substrate with a narrow therapeutic index) disposition in humans is not significant [241]. Therefore, goldenseal's propensity for eliciting herbdrug interactions appears limited to those mediated by CYPs. Dissolution profiles of commercially available goldenseal supplements reveal that berberine and hydrastine are rapidly and completely released from extract formulations [242], producing intestinal luminal concentrations comparable to those required for CYP inhibition in vitro [241]. In humans, both berberine and hydrastine are readily absorbed and extensively metabolized, with berberine phase I metabolites being preferentially sulfated, while those of hydrastine are primarily glucuronidated [243]. Extensive metabolism is conducive to the formation of MI complexes and may explain goldenseal's penchant for CYP inhibition. Given that goldenseal isoquinoline alkaloids significantly inhibit both CYP3A4 and CYP2D6 activity (the two most important drug metabolizing enzymes in humans), its herb-drug interaction potential is deemed considerable.

Interaction risk: high.

\section{Kava kava}

Kava kava (Piper methysticum G. Forst.; family Piperaceae) has long been a traditional beverage consumed among South Pacific islanders to imbue psychotropic, hypnotic, and anxiolytic effects [244]. Since the 1990s, commercial kava extracts formulated as tablets and/or capsules have been marketed as dietary supplements for the alleviation of stress, anxiety, or insomnia [244, 245]. Reports linking kava use to liver toxicity have led to the removal of these products from Australia, Canada, and several European countries, and prompted the FDA to issue warnings of possible hepatotoxic side effects associated with kava supplementation [244]. For those case reports documenting possible kava-related hepatotoxicity, prolonged usage ( $>60$ days), and co-medication with prescription drugs or other botanical supplements were frequent and confounding variables [244]. Modulation of human drug metabolism and/or transport has been postulated as an underlying mechanism for kava-induced liver toxicity. Accordingly, a significant body of literature exists exploring kava's ability to alter XME and transporter activity. The preponderance of in vitro data points to kava as an inhibitor of various CYPs and ABCB1 [79, 245-251], whereas other evidence suggests kava may activate PXR to induce CYP and ABCB1 activity [252-254]. In accordance to kava phytochemicals acting as nuclear receptor ligands, most studies that administered high doses of kava extracts to murine species for prolonged periods observed an induction in CYP1A and 3A activity and expression [250,255-258].

The kavalactones (e.g., kavain, dihydrokavain, methysticin, dihydromethysticin, yangonin, desmethoxyyangonin) are a collection of phytochemicals unique to kava ( Fig. 8). Of these, methysticin and dihydromethysticin are both MDP-PSMs and potent $(\leq 10 \mu \mathrm{M})$ mechanism-based inhibitiors of CYPs in vitro [247,249]. Dihydromethysticin, like some other MDP-containing compounds, also appears to induce CYP3A isoforms in vitro through activation of human PXR [253]. In addition, both methysticin and dihydromethysticin have good dissolution profiles in simulated intestinal fluid at $\mathrm{pH}$ values greater than 4 , a property favorable for producing gut lumen concentrations in excess of $10 \mu \mathrm{M}$ [242]. As a result, one might anticipate that kava supplementation would significantly modulate human XMEs and transporters in vivo. To date, only five prospective clinical studies have attempted to evaluate the drug interaction potential of kava and the results have been mixed $[13,49,232,241,259]$. Russman et al. found that in chronic users of traditional kava-containing beverages (e.g., 7$27 \mathrm{~g}$ kavalactones per week) significantly reduced CYP1A2 activity, yet this practice had no effect on the phenotypic markers of CYP2C19, 2D6, 2E1, or 3A4 function [259]. In contrast, Gurley et al. observed that 30 days of kava supplementation in healthy volunteers had no effect on the phenotypic markers of CYP1A2, CYP2D6, or CYP3A4 activity; however, CYP2E1 activity was significantly reduced [13].

Discrepancies between these studies with regard to kava's effect on CYP1A2 and 2E1 may be traced to variations in extract compo- 
<smiles>COc1cc(/C=C/c2ccc3c(c2)OCO3)oc(=O)c1</smiles><smiles>COC1C=C(C(=O)O)CC(/C=C/c2ccccc2)O1</smiles><smiles>COc1ccc(/C=C/c2cc(OC)cc(=O)o2)cc1</smiles>

Fig. 8 Representative phytochemicals (kava lactones) present in kava kava.<smiles>COc1cc(CCc2ccc3c(c2)OCO3)oc(=O)c1</smiles><smiles>COC1=CC(=O)OC(CCc2ccccc2)C1</smiles><smiles>COc1cc(/C=C/c2ccccc2)oc(=O)c1</smiles><smiles>O=C(/C=C/C=C/c1ccc2c(c1)OCO2)N1CCCCC1</smiles>

Piperine<smiles>CC(C)CNC(=O)/C=C/C=C/c1ccc2c(c1)OCO2</smiles>

Piperlonguminine<smiles>O=C(/C=C/C=C/c1ccc2c(c1)OCO2)N1CCCC1</smiles>

Piperyline<smiles>O=C(/C=C/CCc1ccc2c(c1)OCO2)N1CCCCC1</smiles>

Piperanine (4,5-dihydropiperine)<smiles>O=C(/C=C/C=C/CCc1ccc2c(c1)OCO2)N1CCCCC1</smiles>

Piperdardine (6,7-dihydropiperettine)<smiles>O=C(/C=C/C=C/C=C/c1ccc2c(c1)OCO2)N1CCCCC1</smiles>

Piperettine

Fig. 9 Representative phytochemicals (piperamides) present in black pepper.

sition. Traditional kava beverages are made from aqueous extractions of $P$. methysticum root, whereas formulations of many commercially available kava supplements are products of nonaqueous solvent extractions. Kavalactone profiles can vary considerably among the two extraction processes [245]. Subsequent studies conducted by Gurley's group found that, when compared to known CYP inducers and inhibitors, 14 days of supplementation with well-characterized kava products had no clinically relevant effects on human CYP2D6, CYP3A4, or ABCB1 activity [52,232, 241].

The apparent low potency of methysticin and dihydromethysticin as mechanism-based inhibitors in vivo may stem from the structure of their MDP side chains. In examining a series of MDP-containing compounds, Nakajima et al. noted that those with short, nonbulky side chains were less effective inhibitors of CYP activity [230]. This, coupled with the fact that kava extracts often have lower amounts of methysticin and dihydromethysticin compared to the isoquinoline alkaloid content of goldenseal, may explain the difference in herb-drug interaction potentials for these two MDP-containing species. In short, consumption of commercially available kava supplements per product label recommendations is not likely to affect the efficacy or toxicity of conventional medications.

Interaction risk: low.

\section{Black pepper/piperine}

Dried ground black pepper (Piper nigrum L.; family Piperaceae) has been used since antiquity as both a flavoring agent and medicine [260]. In fact, for almost two millennia Piper species (e.g., $P$. nigrum and $P$. longum) have been essential components of several Ayurvedic medicine preparations [261]. Black pepper is one of the most commonly used spices and may be found on nearly every dinner table in the industrialized world. Black pepper is produced from green unripe berries of the pepper plant; the fruits are dried following a heat treatment that releases browning enzymes from the cell walls [262]. The spiciness of black pepper is due to the MDP-containing phytochemical, piperine, and related pungent alkaloids known as piperamides [260] ( $\bullet$ Fig. 9). These compounds function as insecticides in the pepper plant [263-265], but in mammalian systems they are inhibitors of various XMEs [266-277] and transporters [278-283]. While inhibition is clearly the most prevalent finding, especially upon acute exposure, several animal studies report upregulation of GSTs [284], certain CYPs [285,286], and ABCs [278,280,281] with long-term exposure to piperine, a finding in line with other studies examining chronic feeding of MDP-PSMs.

Piperine's ability to inhibit drug metabolism was first recognized by Atal et al. more than 30 years ago when its administration to rats increased the oral bioavailability of the alkaloids sparteine and vasicine by factors of two and three, respectively [266]. In addition, piperine increased the pharmacodynamic effects of hexobarbital and zoxazolamine in a dose-dependent fashion [266]. 
<smiles>COc1cc2c(c(OC)c1OC)-c1c(cc3c(c1OC)OCO3)C[C@@H](C)[C@](C)(O)C2</smiles>

Gomisin A<smiles>C/C=C(/C)C(=O)OC1c2cc(OC)c(OC)c(OC)c2-c2c(cc3c(c2OC)OCO3)C[C@H](C)[C@]1(C)O</smiles>

Gomisin B<smiles>COc1cc2c(c(OC)c1OC)-c1c(cc3c(c1OC)OCO3)C[C@H](C)[C@](C)(O)[C@@H]2OC(=O)c1ccccc1</smiles>

Gomisin
Fig. 10 Representative methylenedioxyphenylcontaining phytochemicals present in Schisandra species.<smiles>COc1cc2c(c(OC)c1OC)-c1c(cc3c(c1OC)OCO3)C[C@H](C)[C@H]2C</smiles>

g-Schizandrin (d, l-form)<smiles>COc1cc2c(c(OC)c1OC)-c1c(cc3c(c1OC)OCO3)C[C@H](C)[C@](C)(O)C2</smiles>

Schisandrol B<smiles>COc1c2c(cc3c1-c1c(cc4c(c1OC)OCO4)[C@@H](OC(=O)c1ccccc1)[C@](C)(O)[C@@H](C)C3)OCO2</smiles>

Follow-up studies by Atal's group observed that piperine administration was a noncompetitive inhibitor of various murine hepatic monoxygenases as well as UGTs [267]. Subsequent studies confirmed piperine's effect on murine XMEs [268-273] and also found that it and other piperamides were selective inhibitors of human CYP3A4, CYP2D6, and ABCB1 in vitro [274,275,277,282]. Piperine's inhibitory effect on UGTs is more pronounced in intestinal epithelial cells than hepatocytes [270]. Moreover, structureactivity relationship studies involving more than 35 separate analogues revealed that piperine is especially suited for CYP inhibition [273]. Modifications to either the MDP moiety or piperidine side chain significantly reduced its potency [273]. (Millions of years of plant-animal warfare have clearly optimized piperine pharmacology.) In addition to its inhibitory effects on XMEs and $A B C B 1$, piperine may also promote drug absorption by modulating the permeability characteristics of intestinal membranes as well as through stimulating increases in microvilli length [287]. One of the most compelling aspects of piperine is its ability to dramatically enhance the oral absorption of concomitantly administered medications [266,279,283,288-293]. To date, every prospective human trial investigating black pepper's and/or piperine's effect on drug pharmacokinetics has demonstrated a profound improvement in oral bioavailability. Drugs affected and the observed percent increase in mean AUC include phenytoin (16-133\%) [289, 291,292], rifampicin (69\%) [288], propranolol (103\%) [290], theophylline (96\%) [290], and nevirapine (170\%) [293]. In practically every case, piperine's effect can be considered clinically relevant. This is especially so for drugs with narrow therapeutic indices.

Recognizing piperine's utility as a bioavailability enhancer, many dietary supplement manufacturers incorporate $P$. nigrum or $P$. longum extracts into botanical formulations as a means of improving phytochemical efficacy. This positive herb-herb interaction is best exemplified by curcumin, a dietary phytochemical in tumeric with promising chemopreventative properties but exceedingly poor oral bioavailability due to extensive CYP- and
UGT-mediated metabolism [294-295]. When administered with $5 \mathrm{mg}$ of piperine, a twofold increase in curcumin AUC was observed in healthy volunteers [294]. In another study, $20 \mathrm{mg}$ of piperine produced an almost 20 -fold increase in curcumin AUC [296]. Similar bioavailability enhancing effects on green tea polyphenols have also been reported [297]. As an added benefit to enhancing phytochemical bioavailability, piperine also has a broad safety profile [260].

When used in quantities typical for flavoring food, black pepper is not likely to affect the disposition of most medications. However, excessive use of black pepper or intake of dietary supplements formulated with $P$. nigrum or $P$. longum extracts may produce clinically significant interactions with drugs. This may be of particular concern when CYP3A and/or ABCB1 substrates are ingested concomitantly with piperine or piperamides in excess of $10 \mathrm{mg}$.

Interaction risk: high.

\section{Schisandra spp.}

Preparations of fruits from woody vines in the family Schisandraceae are a staple in traditional Chinese, Japanese, and Russian medicine [298]. Among their many uses, berry extracts of Schisandra species [Schisandra chinensis (Turcz.) Baill. and S. sphenanthera Rehder \& E.H. Wilson] are often prescribed for their adaptogenic and hepatoprotective properties [298,299]. In the United States, extracts of $S$. chinensis and $S$. sphenanthera are often incorporated into multicomponent dietary supplement formulations. A host of unique MDP-PSMs including gomisins A-C, schisandrin, schisandrol B, and schisantherin D are found in Schisandra species ( Fig. 10). Like many MDP-PSMs, those present in Schisandra species are modulators of mammalin XMEs and transporters. Recognition of these properties is important as Schisandra products are often taken in conjunction with conventional medications in China, Japan, Russia, and other Asian countries. In addition, dietary supplements containing Schisandra extracts are becoming 
<smiles>CC[C@H]1Oc2ccc([C@@H]3Oc4cc(O)cc(O)c4C(=O)[C@H]3O)cc2O[C@@H]1c1ccc(O)c(OC)c1</smiles><smiles>COc1cc(C2Oc3c(O)cc([C@@H]4Oc5cc(O)cc(O)c5C(=O)C4O)cc3[C@@H]2CO)ccc1O</smiles><smiles>COc1cc(C2C3CO[C@@](O)(C(=O)C3[C@@H]3Oc4cc(O)cc(O)c4C(=O)[C@H]3O)C2C)ccc1O</smiles><smiles>COc1cc([C@H]2Oc3cc([C@@H]4Oc5cc(O)cc(O)c5C(=O)C4O)ccc3O[C@H]2CO)ccc1O</smiles>

Fig. 11 Representative phytochemicals (flavanolignans) present in milk thistle.<smiles>COc1ccc([C@@H]2Oc3ccc([C@@H]4Oc5cc(O)cc(O)c5C(=O)[C@H](O)[C@H]4CO)cc3O2)cc1O</smiles><smiles>O=C1c2c(O)cc(O)cc2O[C@H](c2ccc(O)c(O)c2)[C@H]1O</smiles>

Taxifolin more popular in many Western cultures. This too may increase the chance of Schisandra-related herb-drug interactions.

Ample evidence points to Schisandra MDP-PSMs as both substrates and inhibitors of $A B C$ efflux transporters in vitro [300306]. A number of in vitro studies also point to Schisandra MDPPSMs as both competitive and noncompetitive inhibitors of murine and human CYP isoforms [307-312]. In particular, gomisins $\mathrm{B}, \mathrm{C}$, and $\mathrm{G}$ were shown to be particularly effective inhibitors of human CYP3A4 with $\mathrm{IC}_{50}$ values $<1.5 \mu \mathrm{M}$ [308]. In the presence of NADPH, gomisin C's inactivation of CYP3A4 was time- and concentration-dependent, as well as irreversible, characteristics indicative of mechanism-based inhibition. Moreover, the inhibitory effect of gomisin $C$ was stronger than that of ketoconazole, a known potent CYP3A4 inhibitor [308]. In contrast, reporter gene assays demonstrated that $S$. chinensis extracts and its constituents, schisandrin and schisandrol, activated rat and human PXR [310], whereas certain natural gomisin $\mathrm{H}$ analogues (e.g., tigloylgomisin $\mathrm{H}$, angeloylgomisin $\mathrm{H}$ ) significantly activated phase II detoxification gene expression via the Nrf2 nuclear receptor pathway [313].

Of the available animal studies investigating Schisandra's effect on xenobiotic metabolism, two outcomes emerged (inhibition or induction), each dependent upon the duration of administration. When single doses of Schisandra extracts $(\leq 250 \mathrm{mg} / \mathrm{kg})$ were administered to rats concomitantly with CYP3A and/or ABCB1 substrates (e.g., midazolam [311], nifedipine [309], paclitaxel [314], tacrolimus [312]), drug AUCs more than doubled, suggesting inhibition. However, when administration periods exceeded 6 days, rat XME and transporter function were consistently induced $[310,311,315,316]$.

Unlike the murine study results, prospective clinical trials assessing Schisandra's effect on CYP3A and/or ABCB1 substrate pharmacokinetics were not biphasic. Whether Schisandra was administered once or for up to 14 consecutive days, AUCs of talinolol (ABCB1 substrate) [172], tacrolimus (CYP3A4/ABCB1 substrate) [317,318], and midazolam (CYP3A4 substrate) [319] were increased 1.5-, 2.1-, and 2.0-fold, respectively. Based on these data, it appears that Schisandra is a potent inhibitor, not an inducer, of human XMEs and transporters. Such species differences may stem from the fact that humans not only received lower $\mathrm{mg} / \mathrm{kg}$ doses of Schisandra, but that gomisin C concentrations necessary for PXR activation in humans are twice those required for murine species [311]. Accordingly, the clinical data currently available strongly suggests that Schisandra extracts pose a significant risk for elevating blood levels of drugs that are CYP3A and/or ABCB1 substrates.

Interaction risk: high.

\section{Milk Thistle \\ $\nabla$}

Silybum marianum L. Gaertn. (family Asteraceae), commonly known as milk thistle, is an herbaceous plant native to the Mediterranean region, although it has been naturalized throughout the world [320]. Extracts of milk thistle fruits (achenes) yield a collection of flavanolignans and flavonoids collectively known as silymarin [320,321]. The principal phytochemical components in silymarin are silybin A, silybin B, isosilybin A, isosilybin B, silychristin, isosilychristin, silydianin, and taxifolin [321] (๑ Fig. 11). Milk thistle extracts are touted for their antioxidant and hepatoprotectant properties, and their utility as therapy for treating various liver diseases (e.g., cirrhosis, hepatitis, hepatotoxicity) has been examined in numerous clinical trials [322-326]. While many smaller trials have revealed improvements in various clinical indicies, several larger studies have yielded equivocal results. However, an unequivocal conclusion gleaned from the clinical studies is that milk thistle has an excellent safety profile [322326].

Milk thistle is one of the few popular botanicals in which the pharmacokinetic profile of its principal phytochemicals has been thoroughly examined in humans [327-331]. Components of standard milk thistle extracts, as a general rule, have very low oral bioavailability and short elimination half-lives. This stems from a combination of the poor water solubility of silymarin phy- 
tochemicals coupled with extensive presytemic metabolism (both phase I and II) and biliary secretion. As an example, $\mathrm{C}_{\max }$ values for unconjugated silybin $A$ and $B$ (the two most prevalent flavanolignans in milk thistle products) rarely exceeded $20 \mathrm{ng} /$ $\mathrm{mL}$ for single $600 \mathrm{mg}$ doses of milk thistle extract in healthy volunteers [330]. Even when milk thistle extract $(700 \mathrm{mg})$ was administered every 8 hours for 7 days, the maximum steady state concentrations of silybin A and B rarely exceeded $1.5 \mu \mathrm{g} / \mathrm{mL}$ [331]. At doses exceeding $1500 \mathrm{mg}$ daily, there was also evidence of nonlinear pharmacokinetics [331]. Liver disease, however, does increase milk thistle flavanolignan exposure. Systemic concentrations of silybin and isosilybin diastereomers may be 3-5fold higher in patients with cirrhotic or nonalcoholic fatty liver disease, which may account for milk thistle's purported efficacy in these populations [329,331].

Given its popularity as one of the most utilized botanical supplements in the world, milk thistle's ability to modulate human XMEs and transporters has received considerable attention. A variety of in vitro methodologies have been utilized to assess the effect of milk thistle extracts or individual flavanolignans on XME $[10,36,37,112,332-340]$, ABC efflux transporter $[36,37,112$, 337,341-346], and SLC1B1 uptake transporter [347] activity. The majority of studies are in general agreement that flavanolignan concentrations in excess of $10 \mu \mathrm{M}$ are required for inhibition of most CYP isoforms, and even higher concentrations are needed for $A B C B 1$ and $A B C G 2$ inhibition. Of all the CYP isoforms tested, CYP2C9 appears to be the most sensitive with $\mathrm{IC}_{50}$ values $\sim 8 \mu \mathrm{M}$ for human liver microsomes. At concentrations exceeding $30 \mu \mathrm{M}$, silybin diastereomers have been reported to function as mechanism-based inhibitors of CYP2C9 and 3A4 [336]. UGT1A1, however, may be the XME most easily inhibited by milk thistle with an $\mathrm{IC}_{50}$ value of $1.4 \mu \mathrm{M}$ [336]. SLC1B1 also exhibited an $\mathrm{IC}_{50}$ value less than $4 \mu \mathrm{M}$ for silymarin [347].

Because milk thistle flavanolignans exhibit poor oral bioavailability, several technologies have been employed to enhance this property [348]. One of the more successful has been complexation of silymarin components with phosphatidylcholine. Marketed as Silipide ${ }^{\circledR}$ and Siliphos ${ }^{\circledR}$, these phosphatidylcholine complexes, or phytosomes, exhibit improvements in flavanolignan bioavailability three to five times those of conventional milk thistle extract formulations [348-352]. In addition, recent clinical studies in prostate cancer patients have shown that doses of Siliphos ${ }^{\circledR}$ ranging from 2.5 to 20 grams daily for up to 4 weeks produced $C_{\max }$ values between 10 and $100 \mu \mathrm{M}$ for unconjugated silybin diastereomers $[353,354]$. Conceivably, these concentrations are sufficient for inhibition of various XMEs and efflux transporters, and episodes of hyperbilirubinemia reported in these studies may indeed reflect inhibition of UGT activity $[353,354]$.

To date, a considerable number of prospective human studies have examined milk thistle's drug interaction potential. Supplementation regimens utilizing standard milk thistle extracts had no observable effects on the clinical pharmacokinetics of aminopyrine (nonspecific CYP probe) [355], caffeine (CYP1A2 probe) [50], chlorzoxazone (CYP2E1 probe) [148], debrisoquine (CYP2D6 probe) [49,50], digoxin (ABCB1 substrate) [11], indinavir (CYP3A4 substrate) [356-358], irinotecan (CYP3A4/UGT1A1 substrate) [359], midazolam (CYP3A4 probe) [12,50], nifedipine (CYP3A4 substrate) [360], phenylbutazone (nonspecific CYP probe) [355], ranitidine (CYP3A4/ABCB1 substrate) [361], and rosuvastatin (ABCB1/SLC1A1 substrate) [347]. Taken together, these findings imply that standard milk thistle products generate flavanolignan concentrations in vivo that are incapable of affecting most human
XMEs and transporters. However, a few clinical studies challenge this assumption. For example, 14 days of silymarin supplementation (140 mg thrice daily) increased the AUC of talinolol (ABCB1 substrate) in healthy volunteers by $36 \%$ (a finding suggestive of $A B C B 1$ inhibition); however, this effect is not considered clinically relevant [362]. In contrast, $140 \mathrm{mg}$ of silymarin administered to healthy adults for 9 days reduced the mean AUC for metronidazole (CYP3A4/ABCB1 substrate) by $29 \%$ [363], and while this effect hints at possible induction, it too is of little clinical concern. More concerning is a recent finding that silymarin inhibits the metabolism of losartan to its active metabolite E-3174, and that the magnitude of the interaction is dependent upon CYP2C9 genotype [364]. In subjects with the CYP2C9* $1 /{ }^{*} 1$ genotype, a 14 day course of silymarin produced a 2 -fold increase in losartan AUC and $C_{\max }$, but these parameters were not affected in subjects with the CYP2C9* $1 /^{*} 3$ genotype. This finding supports that of Brantley et al. who noted that CYP2C9 appeared most vulnerable to inhibition by clinically achievable concentrations of silybin $\mathrm{B}$ [340].

At present, no prospective studies have examined the effects of phytosomal milk thistle preparations on the pharmacokinetic profiles of conventional medications. As such, it remains to be seen whether milk thistle products with enhanced bioavailability pose a greater risk for herb-drug interactions. A recent clinical trial of Siliphos ${ }^{\circledR}$ for treatment of chemotherapy-related hepatotoxicity in childhood acute lymphoblastic leukemia suggests otherwise, as investigators observed no adverse interactions between milk thistle and methotrexate, 6-mercaptopurine, or vincristine during the 28-day course of supplementation [365]. Therefore, based upon the existing clinical data, the drug interaction risk for milk thistle products appears minimal.

Interaction risk: low.

\section{St. John's Wort}

$\nabla$

With more than 2000 peer-reviewed articles published on its safety and efficacy, St. John's wort (Hypericum perforatum L.; family Clusiaceae) is the most studied botanical dietary supplement in the world. Hypericum perforatum is a yellow-flowering, perennial herb indigenous to Europe that has been introduced to many temperate areas of the world and grows wild in many meadows. The common name comes from its traditional flowering and harvesting on 24 June, the birthday of John the Baptist (St. John's Day).

Extracts of $H$. perforatum have gained international recognition for their antidepressant activity although the efficacy of many St. John's wort (SJW) products remains questionable [366]. Nevertheless, many clinical trials have demonstrated efficacy superior to placebo and comparable to standard antidepressants but with fewer side effects than conventional antidepressive agents [367]. When used as a single agent, a favorable risk/benefit ratio has made St. John's wort one of the most readily consumed dietary supplements in the world. In turn, the popularity of SJW has also contributed to its distinction as being one of the most problematic dietary supplements with regard to herb-drug interactions.

Both the antidepressant effect and drug interaction potential of SJW hinge upon the extract's content of hyperforin, a bicyclic polyprenylated acylphloroglucinol found exclusively in Hypericum species [368] (O Fig. 12). As an antidepressant, hyperforin functions as broad-based neurotransmitter reuptake inhibitor, affect- 


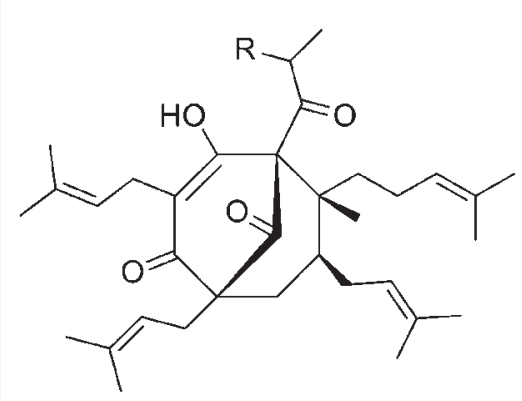

Hyperforin $\mathrm{R}=\mathrm{CH}_{3}$ Adhyperforin $\mathrm{R}=\mathrm{CH}_{2} \mathrm{CH}_{3}$<smiles></smiles>

$\mathrm{R}=\mathrm{CH}_{3}$

$\mathrm{R}=\mathrm{CH}_{2} \mathrm{OH}$ pseudohypericin<smiles>O=c1cc(-c2ccc(O)c(-c3c(O)cc(O)c4c(=O)cc(-c5ccc(O)cc5)oc34)c2)oc2cc(O)cc(O)c12</smiles>

I3',II8-biapigenin (amentoflavone)

Fig. 12 Representative phytochemicals (phloroglucinols, napthodianthrones, flavonoid glycosides) present in St. John's wort.

ing the synaptosomal uptake of serotonin, dopamine, norepinephrine, glutamate, and gamma-aminobutyric acid with similar efficiency. Hyperforin's mode of action appears unique in that the phytochemical does not interact directly with uptake transporters but elevates intracellular sodium concentration, thereby inhibiting gradient-driven neurotransmitter reuptake [368]. As previously mentioned in Part 1 of this review, recent investigations reveal that hyperforin and other SJW-related phytochemicals (e.g., adhyperfroin, hypericins, flavanol glycosides) act synergistically through both pharmacodynamic and pharmacokinetic mechanisms to alleviate depression [369].

While recognized as a natural antidepressant, SJW is equally well known for its ability to induce the activity of several XMEs and transporters, thereby reducing the efficacy of a multitude of prescription medications. As discussed in Part 1 of this review, the clinical severity of SJW-mediated interactions was first recognized in 1999-2000. At that time, several clinics around the world reported that concomitant use of SJW and cyclosporine produced dramatic reductions in blood levels of the immunosuppressant among organ transplant recipients resulting in graft rejection. Since that time, a plethora of clinical studies have borne out SJW's effect on the pharmacokinetics of various medications [370-374].

Hyperforin, a principal mediator of SJW's antidepressive action, lies at the heart of the herb's drug interaction potential. The prenylated phloroglucinol is a high-affinity ligand for human PXR, an orphan nuclear receptor selectively expressed in the liver and intestine that mediates the induction of XME and efflux transporter gene transcription [375-377]. According to one estimate, hyperforin is the most potent PXR activator discovered to date [375], with a half-maximal effective concentration $\left(\mathrm{EC}_{50}\right)$ of $23 \mathrm{nM}$ - a value well below plasma concentrations often achieved in humans $(\sim 100-300 \mathrm{nM})[378,379]$. (Unlike many of the unique phytochemicals described previously, hyperforin is bioavailable and exhibits an elimination half-life of 8-12 hours, thus allowing for significant accumulation with repeated dosing [378, 379].) Of the XMEs and transporters regulated by PXR, those most affected by SJW are CYP subfamilies $2 \mathrm{C}$ and $3 \mathrm{~A}$ as well as several ABC efflux transporters [370-373]. As a result, more than $70 \%$ of all prescription medications are susceptible to SJW-mediated interactions, the consequences of which are decreased oral bioavailability, enhanced systemic clearance, and reduced drug efficacy.
As with all botanicals, phytochemical content can vary considerably and such is the case with hyperforin [380,381]. Most SJW extracts are currently standardized to contain 3\% hyperforin, yet many brands may possess amounts well below this value. Several clinical studies have demonstrated that SJW extracts containing less than $1 \%$ hyperforin are less likely to produce clinically relevant herb-drug interactions [381-384]. Unfortunately for consumers, few SJW products are specifically labeled as having low hyperforin content. Accordingly, to avoid significant drug interactions, consumers should avoid concomitant use of SJW and prescription medications.

In addition to content variability, another factor affecting the magnitude of hyperforin's effect on CYP3A expression and drug efficacy is PXR haplotype. Like many CYPs, PXR is polymorphic, and certain mutations produce significant functional defects in terms of CYP3A transcription. Recent studies indicate that individuals with the $\mathrm{H} 1 / \mathrm{H} 1$ haplotype pair appear more susceptible to SJW-mediated CYP3A induction than subjects with $\mathrm{H} 1 / \mathrm{H} 2$ or H2/H2 pairings [385]. Furthermore, once SJW has been discontinued, as much as a week may be required before CYP3A activity returns to basal levels [386].

SJW's penchant for producing herb-drug interactions has been scrutinized in several recent reviews [370-374]. O Table 1 summarizes those drugs in which SJW produces clinically significant interactions.

Interaction risk: high.

\section{Conclusions and Future Perspectives \\ $\nabla$}

Humans possess a complex system of gastrointestinal XMEs and transporters that are proficient at precluding absorption and facilitating elimination of numerous structurally diverse dietary phytochemicals. As a result, most botanical dietary supplements pose only minimal risks for modulating human drug metabolism. However, several distinct PSMs can either inactivate or highjack the controls of this innate gastrointestinal defense network. MDP-PSMs, functioning as mechanism-based inhibitors of CYPs, may potentiate the toxicity of allopathic medications, whereas potent nuclear receptor ligands like hyperforin may dramatically reduce drug efficacy. What differentiates these PSMs as significant modulators of human drug disposition from the multitude of others is their combination of favorable physicochemical prop- 
Table 1 Drug interactions with St. John's wort confirmed in human studies.

\begin{tabular}{|c|c|c|}
\hline Drug category & Effect of SJW on drug conc. & Reference \\
\hline \multicolumn{3}{|l|}{ Antianginals } \\
\hline Ivabradine & decrease plasma level of drug & [389] \\
\hline \multicolumn{3}{|l|}{ Antiarrhythmics } \\
\hline Digoxin & decrease plasma level of drug & {$[49,390-392]$} \\
\hline \multicolumn{3}{|l|}{ Anticoagulants } \\
\hline Warfarin & decrease plasma level of drug & {$[168,216]$} \\
\hline \multicolumn{3}{|l|}{ Anticonvulsants } \\
\hline Mephenytoin & decrease plasma level of drug & [393] \\
\hline \multicolumn{3}{|l|}{ Antidepressants } \\
\hline Amitriptyline & decrease plasma level of drug & [391] \\
\hline \multicolumn{3}{|l|}{ Antifungals } \\
\hline Voriconazole & decrease plasma level of drug & [394] \\
\hline \multicolumn{3}{|l|}{ Antihistamines } \\
\hline Fexofenadine & $\begin{array}{l}\text { mixed, generally decreases } \\
\text { plasma level of drug }\end{array}$ & [395-397] \\
\hline \multicolumn{3}{|c|}{ Antihyperlipidemics } \\
\hline Simvastatin & decrease plasma level of drug & [398] \\
\hline Atorvastatin & decrease plasma level of drug & [399] \\
\hline \multicolumn{3}{|l|}{ Anxiolytics } \\
\hline Midazolam & decrease plasma level of drug & $\begin{array}{l}{[90,98,384,386,} \\
395,397,400]\end{array}$ \\
\hline Alprazolam & decrease plasma level of drug & {$[401,402]$} \\
\hline Quazepam & decrease plasma level of drug & {$[403]$} \\
\hline \multicolumn{3}{|l|}{ Antivirals } \\
\hline Indinavir & decrease plasma level of drug & [356] \\
\hline Nevirapine & decrease plasma level of drug & [404] \\
\hline \multicolumn{3}{|c|}{$\beta$-adrenergic blockers } \\
\hline Talinolol & decrease plasma level of drug & [405] \\
\hline \multicolumn{3}{|c|}{ Calcium channel blockers } \\
\hline Verapamil & decrease plasma level of drug & {$[406]$} \\
\hline Nifedipine & decrease plasma level of drug & {$[153,385]$} \\
\hline \multicolumn{3}{|c|}{ Cancer chemotherapeutics } \\
\hline Irinotecan & decrease plasma level of drug & {$[407]$} \\
\hline Imatinib & decrease plasma level of drug & {$[408,409]$} \\
\hline \multicolumn{3}{|c|}{ Hormonal contraceptives } \\
\hline Ethinylestradiol & decrease plasma level of drug & [410-412] \\
\hline Norethindrone & decrease plasma level of drug & {$[410,411]$} \\
\hline Ketodesogestrel & decrease plasma level of drug & [412] \\
\hline \multicolumn{3}{|c|}{ Hypoglycemic drugs } \\
\hline Gliclazide & decrease plasma level of drug & [413] \\
\hline \multicolumn{3}{|c|}{ Immunosuppressants } \\
\hline Cyclosporine & decrease plasma level of drug & {$[395,414-416]$} \\
\hline Tacrolimus & decrease plasma level of drug & [417-419] \\
\hline \multicolumn{3}{|l|}{ Opioids } \\
\hline Methadone & decrease plasma level of drug & [420] \\
\hline \multicolumn{3}{|c|}{ Proton pump inhibitors } \\
\hline Omeprazole & decrease plasma level of drug & [421] \\
\hline \multicolumn{3}{|c|}{ Skeletal muscle relaxants } \\
\hline Chlorzoxazone & decrease plasma level of drug & {$[90,98]$} \\
\hline \multicolumn{3}{|c|}{$5 \alpha$-reductase inhibitors } \\
\hline Finasteride & decrease plasma level of drug & [422] \\
\hline
\end{tabular}

erties and unique pharmacophores. As discussed in previous sections, many PSMs modulate human XMEs and transporters in vitro, but due to various factors, this activity is rarely realized in vivo.

Recognizing that poor dissolution characteristics represent major obstacles to phytochemical bioavailability and efficacy, several dietary supplement manufacturers have recently incorporated novel methods of formulating botanical extracts as a means of improving oral absorption [387,388]. Such innovative formulation technologies include liposomes, self-emulsifying microemul- sions, microspheres, phosphatidylcholine complexation (phytosomes), and nanoparticles, as well as the incorporation of piperine as a CYP3A4 and ABCB1 inhibitor [387,388]. In each instance, when compared to conventional extract formulations, the oral bioavailability of various phytochemicals can be increased several fold. To date, no clinical assessments of the herb-drug interaction potential of botanical extracts incorporating these novel formulations have been reported. Accordingly, many botanicals whose drug interaction potential is minimized when administered as conventional dry extracts may increase significantly upon ingestion of formulations utilizing novel delivery systems. Phytochemicals that heretofore had been casualties of man's xenobiotic defense system may emerge as inducers and/or inhibitors of human XMEs and transporters. Improved phytochemical delivery, therefore, may open up a new theater of operations in the "drug war" between humans and plants.

Currently, thousands of botanical supplements are available in the United States and abroad, and hundreds of new products are introduced onto the market each year. Not surprisingly, the vast majority of these botanicals have yet to be evaluated in a clinical setting. From a practical perspective, most may not warrant clinical study; logistics alone clearly preclude such an endeavor. Nevertheless, in vitro studies and compelling case reports suggest that many more botanical supplements may indeed be potent modulators of human drug disposition.

\section{Conflict of Interest \\ $\nabla$}

The authors declare no conflict of interest.

\section{References}

1 Borrelli F, Izzo AA, Ernst E. Pharmacological effects of Cimicifuga racemosa. Life Sci 2003; 73: 1215-1229

2 Huntley A, Ernst E. A systematic review of the safety of black cohosh. Menopause 2003; 10: 58-64

3 Shams T, Setia MS, Hemmings R, McCusker J, Sewitch M, Ciampi A. Efficacy of black cohosh-containing preparations on menopausal symptoms: a meta analysis. Altern Health Med 2010; 16: 36-44

4 Viereck V, Emons G, Wuttke W. Black cohosh: just another phytoestrogen? Trend Endocrinol Metab 2005; 16: 214-221

5 Li JX, Yu ZY. Cimicifugae rhizoma: from origins, bioactive constituents to clinical outcomes. Curr Med Chem 2006; 13: 2927-2951

6 van Breeman RB, Liang W, Banuvar S, Shulman LP, Pang Y, Tao Y, Nikolic $D$, Krock KM, Fabricant DS, Chen S-N, Hedayat S, Bolton JL, Pauli GF, Piersen CE, Krause EC, Geller SE, Farnsworth NR. Pharmacokinetics of 23-epi-26-deoxyactein in women after oral administration of a standardized extract of black cohosh. Clin Pharmacol Ther 2010; 87: 219225

7 Tsukamoto S, Aburatani M, Ohta T. Isolation of CYP3A4 inhibitors from the black cohosh (Cimicifuga racemosa). eCAM 2005; 2: 223-226

8 Huang Y, Jiang B, Nuntanakorn P, Kennelly EJ, Shord S, Lawal TO, Soni KK, Mahady GB. Fukinolic acid derivatives and triterpene glycosides from black cohosh inhibit CYP isozymes, but are not cytotoxic to Hep-G2 cells in vitro. Curr Drug Saf 2010; 5: 118-124

9 Jiang B, Kronenberg F, Nuntanakorn P, Qiu M-H, Kennelly EJ. Evaluation of the botanical authenticity and phytochemical profile of black cohosh products by high-performance liquid chromatography with selected ion monitoring liquid chromatography-mass spectrometry. J Agric Food Chem 2006; 54: 3242-3253

10 Sevior DK, Hokkanen J, Tolonen A, Abass K, Tursas L, Pelkonen O, Ahokas $J T$. Rapid screening of commercially available herbal products for the inhibition of major human hepatic cytochrome P450 enzymes using the N-in-one cocktail. Xenobiotica 2010; 40: 245-254 
11 Gurley BJ, Barone GW, Williams DK, Carrier J, Breen P, Yates CR, Song P, Hubbard MA, Tong Y, Cheboyina S. Effect of milk thistle (Silybum marianum) and black cohosh (Cimicifuga racemosa) supplementation on digoxin pharmacokinetics in humans. Drug Metab Dispos 2006; 34: 69-74

12 Gurley B, Hubbard MA, Williams DK, Thaden J, Tong Y, Gentry WB, Breen $P$, Carrier DJ, Cheboyina S. Assessing the clinical significance of botanical supplementation on human cytochrome P450 3A activity: comparison of a milk thistle and black cohosh product to rifampin and clarithromycin. J Clin Pharmacol 2006; 46: 201-213

13 Gurley BJ, Gardner SF, Hubbard MA, Williams DK, Gentry WB, Khan IA, Shah A. In vivo effects of goldenseal, kava kava, black cohosh, and valerian on human cytochrome P450 1A2, 2D6, 2E1, and 3A4/5 phenotypes. Clin Pharmacol Ther 2005; 77: 415-426

14 Fuchikami H, Satoh $H$, Tsujimoto M, Ohdo S, Ohtani H, Sawada Y. Effects of herbal extracts on the function of human organic anion-transporting polypeptide OATP-B. Drug Metab Dispos 2006; 34: 577-582

15 Basch E, Ulbricht C, Basch S, Dalton S, Ernst E, Foppa I, Szapary P, Tiffany $N$, Orlando CW, Vora M. An evidence-based systematic review of Echinacea (E. angustifolia DC, E. pallida, E. purpurea) by the Natural Standard Research Collaboration. J Herb Pharmacother 2005; 5: 57-88

16 Barnes J, Anderson LA, Gibbons S, Phillipson JD. Echinacea species (Echinacea angustifolia (DC.) Hell., Echinacea pallida (Nutt.) Nutt., Echinacea purpurea (L.) Moench): a review of their chemistry, pharmacology and clinical properties. J Pharm Pharmacol 2005; 57: 929-954

17 Schoop R, Klein P, Suter A, Johnston SL. Echinacea in the prevention of induced rhinovirus colds: a meta analysis. Clin Ther 2006; 28: 174-183

18 Shah SA, Sander S, White CM, Rinaldi M, Coleman CI. Evaluation of Echinacea for the prevention and treatment of the common cold: a meta analysis. Lancet Infect Dis 2007; 7: 473-480

19 Linde K, Barrett B, Bauer R, Melchart D, Woelkart K. Echinacea for preventing and treating the common cold. Cochrane Database Syst Rev 2006: 1: CD000530

20 Christensen LP, Brandt K. Acetylenes and psoralens. In: Crozier A, Clifford MN, Ashihara $\mathrm{H}$, editors. Plant secondary metabolites: occurrence, structure and role in the human diet. Oxford: Blackwell; 2006, 137-173

21 Gilroy CM, Steiner JF, Byers T, Shapiro H, Georgian W. Echinacea and truth in labeling. Arch Intern Med 2003; 163: 699-704

22 Jager H, Meinel L, Dietz B, Lapke C, Bauer R, Merkle HP, Heilmann J. Transport of alkamides from Echinacea species through Caco-2 monolayers. Planta Med 2002; 68: 469-471

23 Matthias A, Blanchfield JT, Penman KG, Toth I, Lang C-S, De Voss JJ, Lehmann RP. Permeability studies of alkylamides and caffeic acid conjugates from Echinacea using a Caco-2 cell monolayer model. J Clin Pharm Ther 2004; 29: 7-13

24 Dietz B, Heilmann J, Bauer R. Absorption of dodeca-2E,4E,8Z,10E/Z-tetraenoic acid isobutylamides after oral application of Echinacea purpurea tincture. Planta Med 2001; 67: 863-864

25 Woelkart K, Koidl C, Grisold A, Gangemi JD, Turner RB, Marth E, Bauer R. Bioavailability and pharmacokinetics of alkamides from the roots of Echinacea angustifolia in humans. J Clin Pharmacol 2005; 45: 683-689

26 Matthias A, Addison RS, Penman KG, Dickinson RG, Bone KM, Lehmann $R P$. Echinacea alkamide disposition and pharmacokinetics in humans after tablet ingestion. Life Sci 2005; 77: 2018-2029

27 Matthias A, Gillam EMJ, Penman KG, Matovic NJ, Bone KM, De Voss JJ, Lehmann RP. Cytochrome P450 enzyme-mediated degradation of Echinacea alkylamides in human liver microsomes. Chem Biol Interact 2005; 155: 62-70

28 Toselli F, Matthias A, Bone KM, Gillam EMJ, Lehmann RP. Metabolism of the major Echinacea alkylamide $N$-isobutyldodeca-2E,4E,8Z,10Z-tetraenamide by human recombinant cytochrome P450 enzymes and human liver microsomes. Phytother Res 2010; 24: 1195-1201

29 Toselli F, Matthias A, Gillam EMJ. Echinacea metabolism and drug interactions: the case for standardization of a complementary medicine. Life Sci 2009; 85: 97-106

30 Budzinski JW, Foster BC, Vandenhoek S, Arnason JT. An in vitro evaluation of human cytochrome P450 3A4 inhibition by selected commercial herbal extracts and tinctures. Phytomedicine 2000; 7: 273-282

31 Foster BC, Vandenhoek S, Hana J, Krantis A, Akhtar MH, Bryan M, Budzinski JW, Ramputh A, Arnason JT. In vitro inhibition of human cytochrome P450-mediated metabolism of marker substrates by natural products. Phytomedicine 2003; 10: 334-342
32 Strandell J, Neil A, Carlin G. An approach to the in vitro evaluation of potential for cytochrome P450 enzyme inhibition from herbals and other natural remedies. Phytomedicine 2004; 11: 98-104

33 Yale SH, Glurich I. Analysis of the inhibitory potential of Ginkgo biloba, Echinacea purpurea, and Serenoa repens on the metabolic activity of cytochrome P450 3A4, 2D6, and 2C9. J Altern Complement Med 2005; 11: 433-439

34 Raner GM, Cornelious S, Moulick K, Wang Y, Mortensen A, Cech NB. Effects of herbal products and their constituents on human cytochrome P450(2E1) activity. Food Chem Toxicol 2007; 45: 2359-2365

35 Hellum BH, Nilsen OG. The in vitro inhibitory potential of trade herbal products on human CYP2D6-mediated metabolism and the influence of ethanol. Basic Clin Pharmacol Toxicol 2007; 101: 350-358

36 Budzinski JW, Trudeau VL, Drouin CE, Panahi M, Arnason JT, Foster BC. Modulation of human cytochrome P450 3A4 (CYP3A4) and P-glycoprotein (P-gp) in Caco-2 cell monolayers by selected commercialsource milk thistle and goldenseal products. Can J Physiol Pharmacol 2007; 85: 966-978

37 Budzinski JW, Foster BC, Trudeau VL, Drouin CE, Bafi-Yeboa N, Arnason $J T$. The interaction of selected phytochemicals, HIV drugs, and commercial-source herbal teas and capsules with human cytochrome P450 3A4 and P-glycoprotein. Pharm Biol 2008; 46: 53-65

38 Hellum BH, Nilsen OG. In vitro inhibition of CYP3A4 metabolism and Pglycoprotein-mediated transport by trade herbal products. Basic Clin Pharmacol Toxicol 2008; 102: 466-475

39 Modarai M, Gertsch J, Suter A, Heinrich M, Kortenkamp A. Cytochrome P450 inhibitory action of Echinacea preparations differs widely and co-varies with alkylamide content. J Pharm Pharmacol 2007; 59: 567-573

40 Hansen TS, Nilsen OG. In vitro CYP3A4 metabolism: inhibition by Echinacea purpurea and choice of substrate for the evaluation of herbal inhibition. Basic Clin Pharmacol Toxicol 2008; 103: 445-449

41 Modarai M, Silva E, Suter A, Herinrich M, Kortenkamp A. Safety of herbal medicinal products: Echinacea and selected alkylamides do not induce CYP3A4 mRNA expression. Evid Based Complement Alternat Med 2011, Article ID 213021, 7 pages; doi: 10.1093/ecam/nep174

42 Modarai M, Yang M, Suter A, Kortenkamp A, Heinrich M. Metabolomic profiling of liquid Echinacea medicinal products with in vitro inhibitory effects on cytochrome P450 3A4 (CYP3A4). Planta Med 2010; 76: $378-385$

43 Romiti N, Pellati F, Nieri P, Benvenuti S, Adinolfi B, Chieli E. P-glycoprotein inhibitory activity of lipophilic constituents of Echinacea pallida roots in a human proximal cell line. Planta Med 2008; 74: 264-266

44 Hansen TS, Nilsen OG. Echinacea purpurea and P-glycoprotein drug transport in Caco-2 cells. Phytother Res 2009; 23: 86-91

45 Mrozikiewicz PM, Bogacz A, Karasiewicz M, Mikolajczak PL, Ozarowsk M, Seremak-Mrozikiewicz A, Czerny B, Bobkiewicz-Kozlowska T, Grzeskowiak $E$. The effect of standardized Echinacea purpurea extract on rat cytochrome P450 expression level. Phytomedicine 2010; 17: 830-833

46 Gorski JC, Huang SM, Mitchell AP, Hamman A, Hilligoss JK, Zaheer NA, Desai M, Miller M, Hall SD. The effect of echinacea (Echinacea purpurea) on cytochrome P450 activity in vivo. Clin Pharmacol Ther 2004; 75: $89-100$

47 Gorski JC, Jones DR, Haehner-Daniels BD, Hamman MA, O'Mara EM, Hal $S D$. The contribution of intestinal and hepatic CYP3A to the interaction between midazolam and clarithromycin. Clin Pharmacol Ther 1998; 64: 133-143

48 Gorski JC, Vannaprasaht S, Hamman MA, Ambrosius WT, Bruce MA, Haehner-Daniels B, Hall SD. The effect of age, sex, and rifampin administration on intestinal and hepatic cytochrome P450 3A activity. Clin Pharmacol Ther 2003; 74: 275-287

49 Gurley BJ, Swain A, Hubbard MA, Williams DK, Barone G, Hartsfield F, Tong Y, Carrier DJ, Cheboyina S, Battu SK. Clinical assessment of CYP2D6-mediated herb-drug interactions in humans: effects of milk thistle, black cohosh, goldenseal, kava kava, St. John's wort, and Echinacea. Mol Nutr Food Res 2008; 52: 755-763

50 Gurley BJ, Gardner SF, Hubbard MA, Williams DK, Gentry WB, Carrier J, Khan IA, Edwards DJ, Shah A. In vivo assessment of botanical supplementation on human cytochrome $\mathrm{P} 450$ phenotypes: Citrus aurantium, Echinacea purpurea, milk thistle, and saw palmetto. Clin Pharmacol Ther 2004; 76: 428-440 
51 Penzak SR, Robertson SM, Hunt JD, Chairez C, Malati CY, Alfaro RM, Stevenson JM, Kovacs JA. Echinacea purpurea significantly induces cytochrome P450 3A activity but does not alter lopinavir-ritonavir exposure in healthy subjects. Pharmacotherapy 2010; 30: 797-805

52 Gurley BJ, Swain A, Williams DK, Barone G, Battu SK. Gauging the clinical significance of P-glycoprotein-mediated herb-drug interactions: comparative effects of St John's wort, echinacea, clarithromycin, and rifampin on digoxin pharmacokinetics. Mol Nutr Food Res 2008; 52: 772-779

53 Freeman C, Spelman K. A critical evaluation of drug interactions with Echinacea spp. Mol Nutr Food Res 2008; 52: 789-798

54 Crozier A, Yokota T, Jaganath IB, Marks SC, Saltmarsh M, Clifford MN. Secondary metabolites in fruits, vegetables, beverages and other plant-based dietary components. In: Crozier A, Clifford MN, Ashihara $\mathrm{H}$, editors. Plant secondary metabolites: occurrence, structure and role in the human diet. Oxford: Blackwell; 2006: 208-302

55 Stevinson C, Pittler MH, Ernst E. Garlic for treating hypercholesterolemia: a meta analysis of randomized clinical trials. Ann Intern Med 2000; 133: 420-429

56 Gardner CD, Lawson LD, Block E, Chatterjee LM, Kiazand A, Balise RR, Kraemer HC. Effect of raw garlic vs. commercial garlic supplements on plasma lipid concentrations in adults with moderate hypercholesterolemia. Arch Intern Med 2007; 167: 346-353

57 Pittler MH, Ernst E. Clinical effectiveness of garlic (Allium sativum). Mol Nutr Food Res 2007; 51: 1382-1385

58 Chen Z-Y, Jiao R, Ma KY. Cholesterol-lowering nutraceuticals and functional foods. J Agric Food Chem 2008; 56: 8761-8773

59 Lawson LD, Wang ZJ, Hughes BG. Identification and HPLC quantitation of the sulfides and dialk(en)yl thiosulfinates in commercial garlic products. Planta Med 1991; 57: 363-370

60 Lawson LD, Gardner CD. Composition, stability, and bioavailability of garlic products used in a clinical trial. J Agric Food Chem 2005; 53 : 6254-6261

61 Amagase $\mathrm{H}$. Clarifying the real bioactive constituents of garlic. J Nutr 2006; 136: 716S-725S

62 Matsuura H. Saponins in garlic as modifiers of the risk of cardiovascular disease. J Nutr 2001; 131: 1000S-1005S

63 Simons LA, Balasubramaniam S, von Konigsmark M, Parfitt A, Simons J, Peters $W$. On the effect of garlic oil on plasma lipids and lipoproteins in mild hypercholesterolaemia. Atherosclerosis 1995; 113: 219-225

64 Berthold HK, Sudhop T, von Bergman K. Effect of a garlic oil preparation on serum lipoproteins and cholesterol metabolism: a randomized controlled trial. JAMA 1998; 279: 1900-1902

65 Smith TJ, Yang CS. Effect of organosulfur compounds from garlic and cruciferous vegetables on drug metabolism enzymes. Drug Metabol Drug Interact 2000; 17: 23-49

66 Yang CS, Chhabra SK, Hong J-Y, Smith TJ. Mechanisms of inhibition of chemical toxicity and carcinogenesis by diallyl sulfide (DAS) and related compounds from garlic. J Nutr 2001; 131: 1041S-1045S

67 Morris CR, Chen SC, Zhou L, Schopfer LM, Ding X, Mirvish SS. Inhibition by allyl sulfides and phenethyl isothiocyanate of methyl-n-pentylnitrosamine depentylation by rat esophageal microsomes, human, and rat CYP2E1, and rat CYP2A3. Nutr Cancer 2004; 48: 54-63

68 Wargovich MJ. Diallylsulfide and allylmethylsulfide are uniquely effective among organosulfur compounds in inhibiting CYP2E1 protein in animal models. J Nutr 2006; 136: 832S-834S

69 Black GP, Collins KS, Blacquiere DP, Forkert P-G. Formation of N-alkylprotoporphyrin IX from metabolism of diallyl sulfone in lung and liver. Drug Metab Dispos 2006; 34: 895-900

70 Haber D, Siess MH, Canivenc-Lavier MC, Le Bon AM, Suschetet M. Differential effects of dietary diallyl sulfide and diallyl disulfide on rat intestinal and hepatic drug-metabolizing enzymes. J Toxicol Environ Health 1995; 44: 423-434

71 Siess M, Le Bon AM, Canivenc-Lavier MC, Suschetet M. Modification of hepatic drug-metabolizing enzymes in rats treated with alkyl sulfides. Cancer Lett 1997; 120: 195-201

72 Wu CC, Sheen LY, Chen H-W, Kuo WW, Tsai SJ, Lii C-K. Differential effects of garlic oil and its three major organosulfur components on the hepatic detoxification system in rats. J Agric Food Chem 2002; 50: 378-383

73 Tsai C-W, Yang J-J, Chen H-W, Sheen L-Y, Lii C-K. Garlic organosulfur compounds upregulate the expression of the pi class of glutathione S-transferase in rat primary hepatocytes. J Nutr 2005; 135: 25602565
74 Zhang P, Noordine M-L, Cherbuy C, Vaugelade P, Pascussi JM, Duée P-H, Thomas $M$. Different activation patterns of rat xenobiotic metabolism genes by two constituents of garlic. Carcinogenesis 2006; 27: 20902095

75 Krizkova J, Burdova K, Hudecek J, Stiborova M, Hodek P. Induction of cytochromes $\mathrm{P} 450$ in small intestine by chemopreventative compounds. Neuro Endocrinol Lett 2008; 29: 717-721

76 Lubet RA, Yao R, Grubbs CJ, You M, Wang Y. Induced expression of drug metabolizing enzymes by preventive agents: role of the antioxidant response element. Chem Biol Interact 2009; 182: 22-28

77 Fisher CD, Augustine LM, Maher JM, Nelson DM, Slitt AL, Klaassen CD, Lehman-McKeeman LD, Cherrington NJ. Induction of drug metabolizing enzymes by garlic and allyl sulfide compounds via activation of constitutive androstane receptor and nuclear factor E2-related factor 2. Drug Metab Dispos 2007; 35: 995-1000

78 Engdal S, Nilsen OG. In vitro inhibition of CYP3A4 by herbal remedies frequently used by cancer patients. Phytother Res 2009; 23: 906-912

79 Zou L, Harkey MR, Henderson GL. Effects of herbal components on cDNA-expressed cytochrome P450 enzyme catalytic activity. Life Sci 2002; 71: 1579-1589

80 Foster BC, Foster MS, Vandenhoek S, Krantis A, Budzinski JW, Arnason JT, Gallicano KD, Choudri S. An in vitro evaluation of human cytochrome P450 3A4 and P-glycoprotein inhibition by garlic. J Pharm Pharmaceut Sci 2001; 4: 176-184

81 Greenblatt DJ, Leigh-Pemberton RA, von Moltke LL. In vitro interactions of water-soluble garlic components with human cytochromes P450. J Nutr 2006; 136: 806S-809S

82 Nabekura T, Kamiyama S, Kitagawa S. Effects of dietary chemopreventative phytochemicals on P-glycoprotein function. Biochem Biophys Res Commun 2005; 327: 866-870

83 Engdal S, Nilsen OG. Inhibition of P-glycoprotein in Caco-2 cells: effects of herbal remedies frequently used by cancer patients. Xenobiotica 2008; 38: 559-573

84 Arora A, Seth K, Shukla Y. Reversal of P-glycoprotein-mediated multidrug resistance by diallyl sulfide in K562 leukemic cells and in mouse liver. Carcinogenesis 2004; 25: 941-949

85 Demeule M, Brossard M, Turcotte S, Regina A, Jodoin J, Béliveau R. Diallyl disulfide, a chemopreventive agent in garlic, induces multidrug resistance-associated protein 2 expression. Biochem Biophys Res Commun 2004; 324: 937-945

86 Berginc K, Zakelj S, Ursic D, Kristl A. Aged garlic extract stimulates Pglycoprotein and multidrug resistance associated protein 2 mediated effluxes. Biol Pharm Bull 2009; 32: 694-699

87 Berginc K, Zakelj S, Kristl A. In vitro interactions between aged garlic extract and drugs used for the treatment of cardiovascular and diabetes patients. Eur J Nutr 2010; 49: 373-384

88 Berginc K, Trontelj J, Kristl A. The influence of aged garlic extract on the uptake of saquinavir and darunavir into HepG2 cells and rat liver slices. Drug Metab Pharmacokinet 2010; 25: 307-313

89 Payen L, Sparfel L, Courtois A, Vernhet L, Guillouzo A, Fardel O. The drug efflux pump MRP-2: regulation of expression in physiopathological situations by endogenous and exogenous compounds. Cell Biol Toxicol 2002; 18: 221-233

90 Gurley BJ, Gardner SF, Hubbard MA, Williams DK, Gentry WB, Cui Y, Ang CYW. Cytochrome P450 phenotypic ratios for predicting herb-drug interactions in humans. Clin Pharmacol Ther 2002; 72: 276-287

91 Gwilt PR, Lear CL, Tempero MA, Birt DD, Grandjean AC, Ruddon RW, Nagel $D L$. The effect of garlic extract on human metabolism of acetaminophen. Cancer Epidemiol Biomarkers Prev 1994; 3: 155-160

92 Loizou GD, Crocker J. The effects of alcohol and diallyl sulphide on CYP2E1 activity in humans: a phenotyping study using chlorzoxazone. Hum Exp Toxicol 2001; 20: 321-327

93 Piscitelli SC, Burstein AH, Welden N, Gallicano KD, Falloon J. The effect of garlic supplements on the pharmacokinetics of saquinavir. Clin Infect Dis 2002; 34: 234-238

94 Gallicano K, Foster B, Choudri S. Effect of short-term administration of garlic supplements on single-dose pharmacokinetics in healthy volunteers. Br J Clin Pharmacol 2003; 55: 199-202

95 Markowitz JS, DeVane L, Chavin KD, Taylor RM, Ruan Y, Donovan JL. Effects of garlic (Allium sativum L.) supplementation on cytochrome P450 2D6 and 3A4 activity in healthy volunteers. Clin Pharmacol Ther 2003; 74: 170-177 
96 Jacek H, Rentsch KM, Steinert HC, Pauli-Magnus C, Meier PJ, Fattinger K. No effect of garlic extract on saquinavir kinetics and hepatic CYP3A4 function measured by the erythromycin breath test [Abstr]. Clin Pharmacol Ther 2004; 75: 80

97 Jabbari A, Argani H, Ghorbanihaghjo A, Mahdavi R. Comparison between swallowing and chewing of garlic on levels of serum lipids, cyclosporine, creatinine and lipid peroxidation in renal transplant recipients. Lipids Health Dis 2005; 4: 11

98 Gurley BJ, Gardner SF, Hubbard MA, Williams DK, Gentry WB, Cui Y, Ang CYW. Clinical assessment of effects of botanical supplementation on cytochrome P450 phenotypes in the elderly: St John's wort, garlic oil, Panax ginseng and Ginkgo biloba. Drugs Aging 2005; 22: 525-539

99 Cox MC, Low J, Lee J, Walshe J, Denduluri N, Berman A, Permenter MG, Petros WP, Proce DK, Figg WD, Sparreboom A, Swain SM. Influence of garlic (Allium sativum) on the pharmacokinetics of docetaxel. Clin Cancer Res 2006; 12: 4636-4640

100 Macan H, Uykimpang R, Alconcel M, Takasu J, Razon R, Amagase H, Niihara Y. Aged garlic extract may be safe for patients on warfarin therapy. J Nutr 2006; 136: 793S-795S

101 Abdul MIM, Jiang X, Willaims KM, Day RO, Roufogalis BD, Liauw WS, $\mathrm{Ku} \mathrm{H}$, McLachlan AJ. Pharmacodynamic interaction of warfarin with cranberry but not with garlic in healthy subjects. $\mathrm{Br} \mathrm{J}$ Pharmacol 2008; 154: 1691-1700

102 Yang L-J, Fan L, Liu Z-Q, Mao Y-M, Guo D, Liu L-H, Tan Z-R, Peng L, Han C-T, Hu D-L, Wang D, Zhou H-H. Effects of allicin on CYP2C19 and CYP3A4 activity in healthy volunteers with different CYP2C19 genotypes. Eur J Clin Pharmacol 2009; 65: 601-608

103 Hajda J, Rentsch KM, Gubler C, Steinert H, Stieger B, Fattinger K. Garlic extract induces intestinal P-glycoprotein, but exhibits no effect on intestinal and hepatic CYP3A4 in humans. Eur J Pharm Sci 2010; 41: 729-735

104 Chan P-C, Xia Q Fu PP. Ginkgo biloba leaves extract: biological, medicinal, and toxicological effects. J Environ Sci Health C 2007; 25: 211-244

105 Zhou W, Chai H, Lin PH, Lumsden AB, Yao Q Chen C. Clinical use and molecular mechanisms of action of extract of Ginkgo biloba leaves in cardiovascular diseases. Cardiovasc Drug Rev 2004; 22: 309-319

106 Canter PH, Ernst E. Ginkgo biloba is not a smart drug: an updated systematic review of randomized clinical trials testing the nootropic effects of G. biloba extracts in healthy people. Hum Psychopharmacol 2007; 22: 265-278

107 Ramassamy C, Longpré F, Christen Y. Ginkgo blioba extract (EGb 761) in Alzheimer's disease: is there any evidence? Curr Alzheimer Res 2007; 4: $253-262$

108 Birks J, Grimley Evans J. Ginkgo biloba for cognitive impairment and dementia. Cochrane Database Syst Rev 2009; 1: CD003120

109 Nicolaï SP, Kruidenier LM, Bendermacher BL, Prins MH, Teijink JA. Ginkgo biloba for intermittent claudication. Cochrane Database Syst Rev 2009; 2: CD006888

110 Kressman S, Müller WE, Blume HH. Pharmaceutical quality of different Ginkgo biloba brands. J Pharm Pharmacol 2002; 54: 661-669

111 Woelkert K, Feizlmayr E, Dittrich P, Beubler E, Pinl F, Suter A, Bauer R. Pharmacokinetics of bilobalide, ginkgolide A and B after administration of three different Ginkgo biloba L. preparations in humans. Phytother Res 2010; 24: 445-450

112 Etheridge AS, Black SR, Patel PR, So J, Mathews JM. An in vitro evaluation of cytochrome P450 inhibition and P-glycoprotein interaction with goldenseal, Ginkgo biloba, grape seed, milk thistle, and ginseng extracts and their constituents. Planta Med 2007; 73: 731-741

113 Hellum BH, Hu Z, Nilsen OG. The induction of CYP1A2, CYP2D6 and CYP3A4 by six trade herbal products in cultured primary human hepatocytes. Basic Clin Pharmacol Toxicol 2007; 100: 23-30

114 Hellum $B H, H u$ Z, Nilsen OG. Trade herbal products and induction of CYP2C19 and CYP2E1 in cultured human hepatocytes. Basic Clin Pharmacol Toxicol 2009; 105: 58-63

115 Gaudineau C, Beckerman R, Welbourn S, Auclair K. Inhibition of human P450 enzymes by multiple constituents of the Ginkgo biloba extract. Biochem Biophys Res Commun 2004; 318: 1072-1078

116 Chang TKH, Chen J, Yeung EYH. Effect of Ginkgo biloba extract on procarcinogen-bioactivating human CYP1 enzymes: identification of isorhamnetin, kaempferol, and quercetin as potent inhibitors of CYP1B1. Toxicol Appl Pharmacol 2006; 213: 18-26

117 Numa AM, Abbott FS, Chang TKH. Effect of Ginkgo biloba extract on oxidative metaolism of valproic acid in hepatic microsomes from donors with the CYP2C9*1/*1 genotype. Can J Physiol Pharmacol 2007; 85: $848-855$
118 Lau AJ, Chang TKH. Inhibition of human CYP2B6-catalyzed bupropion hydroxylation by Ginkgo biloba extract: effect of terpene trilactones and flavonols. Drug Metab Dispos 2009; 37: 1931-1937

119 Mohamed MF, Frye RF. Inhibition of intestinal and hepatic glucuronidation of mycophenolic acid by Ginkgo biloba extract and flavonoids. Drug Metab Dispos 2010; 38: 270-275

$120 \mathrm{He}$ N, Edeki T. The inhibitory effects of herbal components on CYP2C9 and CYP3A4 catalytic activities in human liver microsomes. Am J Ther 2004; 11: 206-212

121 Kimura $Y$, Ito $H$, Ohnishi $R$, Hatano $T$. Inhibitory effects of polyphenols on human cytochrome P450 3A4 and 2C9 activity. Food Chem Toxicol 2010; 48: 429-435

122 Tiong KH, Yiap BC, Tan EL, Ismail R, Ong CE. In vitro modulation of naturally occurring flavonoids on cytochrome P450 2A6 (CYP2A6) activity. Xenobiotica 2010; 40: 458-466

123 Kuo IF, Chen J, Chang TKH. Effect of Ginkgo biloba extract on rat hepatic microsomal CYP1A activity: role of ginkgolides, bilobalide, and flavonols. Can J Physiol Pharmacol 2004; 82: 57-64

124 von Moltke LL, Weemhoff JL, Bedir E, Khan IA, Harmatz JS, Goldman P, Greenblatt DJ. Inhibition of human cytochromes $\mathrm{P} 450$ by components of Ginkgo biloba. J Pharm Pharmacol 2004; 56: 1039-1044

125 Hodek P, Trefil P, Stiborová M. Flavonoids-potent and versatile biologically active compounds interacting with cytochromes P450. Chem Biol Interact 2002; 139: 1-21

126 Si D, Wang Y, Zhou Y-H, Guo Y, Wang J, Zhou H, Li Z-S, Fawcett JP. Mechanism of CYP2C9 inhibition by flavones and flavonols. Drug Metab Dispos 2009; 37: 629-634

127 He N, Xie H-G, Collins X, Edeki T, Yan Z. Effects of individual ginsenosides, ginkgolides and flavonoids on CYP2C19 and CYP2D6 activity in human liver microsomes. Clin Exp Pharmacol Physiol 2006; 33: 813815

128 Chang TKH, Chen J, Teng XW. Distinct role of bilobalide and ginkgolide $\mathrm{A}$ in the modulation of rat CYP2B1 and CYP3A23 gene expression by Ginkgo biloba extract in cultured hepatocytes. Drug Metab Dispos 2006; 34: 234-242

129 Yeung EYH, Sueyoshi T, Negishi M, Chang THK. Identification of Ginkgo biloba as a novel activator of pregnane X receptor. Drug Metab Dispos 2008; 36: 2270-2276

130 Deng Y, Bi HC, Zhao LZ, Wang XD, Chen J, Ou ZM, Ding L, Xu LJ, Guan S, Chen $X$, Zhou SF, Huang $M$. Induction of cytochrome P450 3A by the Ginkgo biloba extract and bilobalides in human and rat primary hepatocytes. Drug Metab Lett 2008; 2: 60-66

131 Li L, Stanton JD, Tolson AH, Luo Y, Wang H. Bioactive terpenoids and flavonoids from Ginkgo biloba extract induce the expression of hepatic drug-metabolizing enzymes through pregnane $\mathrm{X}$ receptor, constitutive androstane receptor, and aryl hydrocarbon receptor-mediated pathways. Pharm Res 2009; 26: 872-882

132 Rajaraman G, Yang G, Chen J, Chang THK. Modulation of CYP1B1 and CYP1A1 gene expression and activation of aryl hydrocarbon receptor by Ginkgo biloba extract in MCF-10A human mammary epithelial cells. Can J Physiol Pharmacol 2009; 87: 674-683

133 Satsu H, Hiura Y, Mochizuki K, Hamada M, Shimizu M. Activation of pregnane $\mathrm{X}$ receptor and induction of MDR1 by dietary phytochemicals. J Agric Food Chem 2008; 56: 5366-5373

134 Jeuken A, Keser BJG, Khan E, Brouwer A, Koeman J, Denison MS. Activation of the Ah receptor by extracts of dietary herbal supplements, vegetables, and fruits. J Agric Food Chem 2003; 51: 5478-5487

135 Sasaki K, Hatta S, Wada K, Ueda N, Yoshimura T, Endo T, Sakata M, Tanaka T, Haga M. Effects of extract of Ginkgo biloba leaves and its constituents on carcinogen-metabolizing enzyme activities and glutathione levels in mouse liver. Life Sci 2002; 70: 1657-1667

136 Umegaki K, Saito K, Kubota Y, Sanada H, Yamada K, Shinozuka K. Ginkgo biloba extract markedly induces pentoxyresorufin O-dealkylase activity in rats. Jpn J Pharmacol 2002; 90: 345-351

137 Yang XF, Wang NP, Lu WH, Zeng FD. Effects of Ginkgo biloba extract and tanshinone on cytochrome P-450 isozymes and glutathione transferase in rats. Acta Pharmacol Sin 2003; 24: 1033-1038

138 Sugiyama T, Kubota Y, Shinozuka K, Yamada S, Yamada K, Umegaki K. Induction and recovery of hepatic drug metabolizing enzymes in rats treated with Ginkgo biloba extract. Food Chem Toxicol 2004; 42: 953957

139 Chatterjee SS, Doelman CJ, Nöldner M, Biber A, Koch E. Influence of the Ginkgo extract EGb 761 on rat liver cytochrome P450 and steroid metabolism and excretion in rats and man. J Pharm Pharmacol 2005; 57: 641-650 
140 Guo L, Mei N, Liao W, Chan P-C, Fu PP. Ginkgo biloba extract induces gene expression changes in xenobiotics metabolism and the Myccentered network. Omics 2010; 14: 75-89

141 Shinozuka K, Umekagi K, Kubota Y, Tanaka N, Mizuno H, Yamauchi J, Nakamura K, Kunitomo M. Feeding of Ginkgo biloba extract (GBE) enhances gene expression of hepatic cytochrome P-450 and attenuates the hypotensive effect of nicardipine in rats. Life Sci 2002; 70: 27832792

142 Sugiyama T, Kubota Y, Shinozuka K, Yamada S, Wu J, Umegaki K. Ginkgo biloba extract modifies hypoglycemic action of tolbutamide via hepatic cytochrome P450 mediated mechanism in aged rats. Life Sci 2004; 75: 1113-1122

143 Kubota Y, Kobayashi K, Tanaka N, Nakamura K, Kunimoto M, Umegaki K, Shinozuka K. Pretreatment with Ginkgo biloba extract weakens the hypnosis action of phenobarbital and its plasma concentration in rats. J Pharm Pharmacol 2004; 56: 401-405

144 Zhao L-Z, Huang M, Chen J, Ee PLR, Chan E, Duan W, Guan Y-Y, Hong $Y-H$, Chen X, Zhou S. Induction of propranolol metabolism by Ginkgo biloba extract EGb 761 in rats. Curr Drug Metab 2006; 7: 577-587

145 Yang CY, Chao PDL, Hou YC, Tsai SY, Wen KC, Hsiu SL. Marked decrease of cyclosporine bioavailability caused by coadministration of ginkgo and onion in rats. Food Chem Toxicol 2006; 44: 1572-1578

146 Tang J, Sun J, Zhang Y, Li L, Cui F, He Z. Herb-drug interactions: effect of Ginkgo biloba extract on the pharmacokinetics of theophylline in rats. Food Chem Toxicol 2007; 45: 2441-2445

147 Rajaraman G, Chen J, Chang TKH. Ginkgolide A contributes to the potentiation of acetaminophen toxicity by Ginkgo biloba extract in primary cultures of rat hepatocytes. Toxicol Appl Pharmacol 2006; 217: 225-233

148 Umegaki K, Taki Y, Endoh K, Taku K, Tanabe H, Shinozuka K, Sugiyama T. Bilobalide in Ginkgo biloba extract is a major substance inducing hepatic CYPs. J Pharm Pharmacol 2007; 59: 871-877

149 Deng Y, Bi H-C, Zhao L-Z, He F, Liu Y-Q Yu J-J, Ou Z-M, Ding L, Huang Z-Y, Huang $M$, Zhou S-F. Induction of cytochrome P450s by terpene trilactones and flavonoids of the Ginkgo biloba extract EGb 761 in rats. Xenobiotica 2008; 38: 465-481

150 Taki Y, Yamazaki Y, Shimura F, Yamada S, Umegaki K. Time-dependent induction of hepatic cytochrome P450 enzyme activity and mRNA expression by bilobalide in rats. J Pharmacol Sci 2009; 109: 459-462

151 Yin OQP, Tomlinson B, Waye MMY, Chow AHL, Chow MSS. Pharmacogenetics and herb-drug interactions: experience with Ginkgo biloba and omeprazole. Pharmacogenetics 2004; 14: 841-850

152 Duche JC, Barre J, Guinot P, Duchier J, Cournot A, Tillement JP. Effect of Ginkgo biloba extract on microsomal enzyme induction. Int J Clin Pharm Res 1989; 9: 165-168

153 Smith M, Lin KM, Zheng YP. An open trial of nifedipine-herb interactions: nifedipine with St John's wort, ginseng, or Ginkgo biloba [Abstr.]. Clin Pharmacol Ther 2001; 69: P86

154 Sun H, Zuo Z, Yin OQ Tomlinson B, Chow MS. A high-throughput cocktail method for screening the effect of herbal product on liver isozyme activities: experience with Ginkgo biloba. Clin Pharmacol Ther 2002; 71: P100

155 Engelsen J, Nielsen JD, Winther K. Effect of coenzyme Q10 and Ginkgo biloba on warfarin dosage in stable, long-term warfarin treated outpatients. A randomized, double blind, placebo-crossover trial. Thromb Haemost 2002; 87: 1075-1076

156 Mauro VF, Mauro LS, Kleshinski JF, Khuder SA, Wang Y, Erhardt PW. Impact of Ginkgo biloba on the pharmacokinetics of digoxin. Am J Ther 2003; 10: 247-251

157 Markowitz JS, Donovan JL, DeVane L, Sipkes L, Chavin KD. Multipledose administration of Ginkgo biloba did not affect cytochrome P-450 2D6 or 3A4 activity in normal volunteers. J Clin Psychopharmacol 2003; 23: 576-581

158 Yoshioka M, Ohnishi N, Koishi T, Obata Y, Nakagawa M, Matsumoto T, Tagagi K, Takara K, Ohkuni T, Yokoyama T, Kuroda K. Studies on interactions between functional foods or dietary supplements and medicines. IV. Effects of Ginkgo biloba leaf extract on the pharmacokinetics and pharmacodynamics of nifedipine in healthy volunteers. Biol Pharm Bull 2004; 27: 2006-2009

159 Yasui-Furukori N, Furukori H, Kaneda A, Kaneko S, Tateishi T. The effects of Ginkgo biloba extracts on the pharmacokinetics and pharmacodynamics of donepezil. J Clin Pharmacol 2004; 44: 538-542
160 Jiang X, Williams KM, Liauw WS, Ammit AJ, Roufogalis BD, Duke CC, Day $R O$, McLachlan AJ. Effect of ginkgo and ginger on the pharmacokinetics and pharmacodynamics of warfarin in healthy subjects. Br J Clin Pharmacol 2005; 59: 425-432

161 Markowitz JS, DeVane CL, Lewis JG, Chavin KD, Wang J-S, Donovan JL. Effect of Ginkgo biloba extract on plasma steroid concentrations in healthy volunteers: a pilot study. Pharmacotherapy 2005; 25: 13371340

162 Aruna D, Naidu MUR. Pharmacodynamic interaction studies of Ginkgo biloba with cilostazol and clopidogrel in healthy human subjects. $\mathrm{Br}$ J Clin Pharmacol 2006; 63: 333-338

163 Mohutsky MA, Anderson GD, Miller JW, Elmer GW. Ginkgo biloba: evaluation of CYP2C9 drug interactions in vitro and in vivo. Am J Ther 2006; $13: 24-31$

164 Greenblatt DJ, von Moltke LL, Luo Y, Perloff ES, Horan KA, Bruce A, Reynolds RC, Harmatz JS, Avula B, Khan IA, Goldman P. Ginkgo biloba does not alter clearance of flurbiprofen, a cytochrome P450-2C9 substrate. J Clin Pharmacol 2006; 46: 214-221

165 Lu W-J, Huang J, Lai M-L. The effects of ergoloid mesylates and Ginkgo biloba on the pharmacokinetics of ticlopidine. J Clin Pharmacol 2006; 46: 628-634

166 Uchida S, Yamada H, Li XD, Maruyama S, Ohmori Y, Oki T, Watanabe H, Umegaki K, Ohashi K, Yamada S. Effects of Ginkgo biloba extract on pharmacokinetics and pharmacodynamics of tolbutamide and midazolam in healthy volunteers. J Clin Pharmacol 2006; 46: 1290-1298

167 Wolf HRD. Does Ginkgo biloba special extract EGb 761 provide additional effects on coagulation and bleeding when added to acetylsalicylic acid $500 \mathrm{mg}$ daily? Drugs R D 2006; 7: 163-172

168 Jiang X, Blair EYL, McLachlan AJ. Investigation of the effects of herbal medicines on warfarin response in healthy subjects: a population pharmacokinetic-pharmacodynamic modeling approach. J Clin Pharmacol 2006; 46: 1370-1378

169 Kudolo GB, Wang W, Javors M, Blodgett J. The effect of the ingestion of Ginkgo biloba extract (EGb 761) on the pharmacokinetics of metformin in non-diabetic and type 2 diabetic subjects - A double blind placebo-controlled, crossover study. Clin Nutr 2006; 25: 606-616

170 Robertson SM, Davey RT, Voell J, Formentini E, Alfaro RM, Penzak SR. Effect of Ginkgo biloba extract on lopinavir, midazolam, and fexofenadine pharmacokinetics in healthy subjects. Curr Med Res Opin 2008; 24: 591-599

171 Lei HP, Wang G, Wang LS, Ou-yang D, Chen H, Zhang W, Tan Z-R, Fan L, $\mathrm{He} Y$-J, Zhou H-H. Lack of effect of Ginkgo biloba on voriconazole pharmacokinetics in Chinese volunteers identified as CYP2C19 poor and extensive metabolizers. Ann Pharmacother 2009; 43: 726-731

172 Fan L, Mao X-Q Tao GY, Wang G, Jiang F, Chen Y, Li Q Zhang W, Lei H-P, $H u$ DL, Huang Y-F, Wang D, Zhou H-H. Effect of Schisandra chinensis extract and Ginkgo biloba extract on the pharmacokinetics of talinolol in healthy volunteers. Xenobiotica 2009; 39: 249-254

173 Fan L, Tao G-Y, Wang G, Chen Y, Zhang W, He Y-J, Li Q Lei H-P, Jiang F, Hu D-L, Huang Y-F, Zhou H-H. Effects of Ginkgo biloba extract ingestion on the pharmcokinetics of talinolol in healthy Chinese volunteers. Ann Pharmacother 2009; 43: 944-949

174 Lei H-P, Ji W, Lin J, Chen H, Tan Z-R, Hu D-L, Liu L-J, Zhou H-H. Effects of Ginkgo biloba extract on the pharmacokinetics of bupropion in healthy volunteers. Br J Clin Pharmacol 2009; 68: 201-206

175 Zuo X-C, Zhang B-K, Jia S-J, Liu S-K, Zhou L-Y, Li J, Zhang J, Dai L-L, Chen $B-M$, Yang G-P, Yuan H. Effects of Ginkgo biloba extracts on diazepam metabolism: a pharmacokinetic study in healthy Chinese male subjects. Eur J Clin Pharmacol 2010; 66: 503-509

176 Kim B-H, Kim K-P, Lim KS, Kim J-R, Yoon SH, Cho J-Y, Lee Y-O, Lee K-H, Jang I-J, Shin S-G, Yu K-S. Influence of Ginkgo biloba extract on the pharmacodynamic effects and pharmacokinetic properties of ticlopidine: an open-label, randomized, two-period, two-treatment, two-sequence, single-dose crossover study in healthy Korean male volunteers. Clin Ther 2010; 32: 380-390

177 Food and Drug Administration. Drug Interaction Studies - Study Design, Data Analysis, and Implications for Dosing and Labeling. Available at http://www.fda.gov/Drugs/Guidance Compliance Regulatory Information/Guidances/ucm064982.htm. Accessed 2010 Jul 17

178 Huang SM, Temple R, Throckmorton DC, Lesko LJ. Drug interaction studies: study design, data analysis, and implications for dosing and labeling. Clin Pharmacol Ther 2007; 81: 298-304 
179 Lau AJ, Yang G, Rajaraman, Baucom CC, Chang TKH. Species-dependent and receptor-selective action of bilobalide on the function of constitutive androstane receptor and preganane $\mathrm{X}$ receptor. Drug Metab Dispos 2012; 40: 178-186

180 Mauri P, Simonetti P, Gardana C, Minoggio M, Morazzoni P, Bombardelli E, Pietta P. Liquid chromatography/atmospheric pressure chemical ionization mass spectrometry of terpene lactones in plasma of volunteers dosed with Ginkgo biloba L. extracts. Rapid Commun Mass Spectrom 2001; 15: 929-934

181 Biber A. Pharmacokinetics of Ginkgo biloba extracts. Pharmacopsychiatry 2003; 36: S32-S37

182 Woelkart K, Feizlmayr E, Dittrich P, Beubler E, Pinl F, Suter A, Bauer R. Pharmacokinetics of bilobalide, ginkgolide A and B after administration of three different Ginkgo biloba L. preparations in humans. Phytother Res 2010; 24: 445-450

183 Kressmann S, Müller WE, Blume HH. Pharmaceutical quality of different Ginkgo biloba brands. J Pharm Pharmacol 2002; 54: 661-669

184 Kressmann S, Biber A, Wonnemann M, Schug B, Blume HH, Müller WE. Influence of pharmaceutical quality on the bioavailability of active components from Ginkgo biloba preparations. J Pharm Pharmacol 2002; 54: 1507-1514

185 Madgula VL, Avula B, Yu YB, Tchantchou F, Fisher S, Luo Y, Khan IA, Khan SI. Intestinal and blood-brain barrier permeability of ginkgolides and bilobalide: in vitro and in vivo approaches. Planta Med 2010; 76: 599606

186 Jia L, Zhao Y, Liang X-J. Current evaluation of the millennium phytomedicine - ginseng (II): collected chemical entities, modern pharmacology, and clinical applications emanated from traditional Chinese medicine. Curr Med Chem 2009; 16: 2924-2942

187 Vogler BK, Pittler MH, Ernst E. The efficacy of ginseng. A systematic review of randomized clinical trials. Eur J Clin Pharmacol 1999; 55: 567-575

188 Buettner C, Yeh GY, Phillips RS, Mittleman MA, Kaptchuk TJ. Systematic review of the effects of ginseng on cardiovascular risk factors. Ann Pharmacother 2005; 39: 83-95

189 Luo JZ, Luo L. Ginseng on hyperglycemia: effects and mechanisms. eCAM 2009; 6: 423-427

190 Christensen LP. Ginsenosides: chemistry, biosynthesis, analysis, and potential health effects. Adv Food Nutr Res 2008; 55: 1-99

191 Chen C, Choiu W, Zhang J. Comparison of the pharmacological effects of Panax ginseng and Panax quinquefolium. Acta Pharmacol Sin 2008; 29: $1103-1108$

192 Tawab MA, Bahr U, Karas M, Wurglics M, Schubert-Zsilavecz M. Degradation of ginsenosides on humans after oral administration. Drug Metab Dispos 2003; 31: 1065-1071

193 Bae E-A, Han MJ, Kim E-J, Kim D-H. Transformation of ginseng saponins to ginsenoside Rh2 by acids and human intestinal bacteria and biological activities of their transformants. Arch Pharm Res 2004; 27: 61-67

194 Lee J, Lee E, Kim D, Lee J, Yoo J, Koh B. Studies on absorption, distribution and metabolism of ginseng in humans after oral administration. J Ethnopharmacol 2009; 122: 143-148

195 Ling Y, Yong L, Chang-Xiao L. Metabolism and pharmacokinetics of ginsenosides. Asian J Pharmacodynam Pharmacokinet 2006; 6: 103-120

196 Hasegawa $\mathrm{H}$. Proof of the mysterious efficacy of ginseng: basic and clinical trials: metabolic activation of ginsenoside; deglycosylation by intestinal bacteria and esterification with fatty acid. J Pharmacol Sci 2004; 95: 153-157

197 Han M, Fang X. Difference in oral absorption of ginsenoside Rg1 between in vitro and in vivo models. Acta Pharmacol Sin 2006; 27: 499-505

198 Xie H-T, Wang G-J, Chen M, Jiang X, Li H, Lv H, Huang C-R, Wang R, Roberts $M$. Uptake and metabolism of ginsenoside Rh2 and its aglycon protopanaxadiol by Caco-2 cells. Biol Pharm Bull 2005; 28: 383-386

199 Gu Y, Wang G-J, Wu X-L, Zheng Y-T, Zhang J-W, Ai H, Sun J-G, Jia Y-W. Intestinal absorption mechanisms of ginsenoside Rh2: stereoselectivity and involvement of ABC transporters. Xenobiotica 2010; 40: 602612

200 Henderson GL, Harkey MR, Gershwin ME, Hackman RM, Stern JS, Stresser DM. Effects of ginseng components on c-DNA-expressed cytochrome P450 enzyme catalytic activity. Pharmacol Lett 1999; 65: 209-214
201 Chang TKH, Chen J, Benetton SA. In vitro effect of standardized ginseng extracts and individual ginsenosides on the catalytic activity of human CYP1A1, CYP1A2, and CYP1B1. Drug Metab Dispos 2002; 30: 378-384

202 Kim S-W, Kwon H, Chi D-W, Shim J-H, Park J-D, Lee Y-H, Pyo S, Rhee D-K. Reversal of P-glycoprotein-mediated multidrug resistance by ginsenoside $\mathrm{Rg}_{3}$. Biochem Pharmacol 2003; 65: 75-82

203 Liu Y, Zhang J-W, Li W, Ma H, Sun J, Deng M-C, Yang L. Ginsenoside metabolites, rather than naturally occurring ginsenosides, lead to inhibition of human cytochrome P450 enzymes. Toxicol Sci 2006; 91: 356-364

204 Liu Y, Ma H, Zhang JW, Deng MC, Yang L. Influence of ginsenoside Rh1 and $\mathrm{F} 1$ on human cytochrome p450 enzymes. Planta Med 2006; 72: 126-131

205 Jin J, Shahi S, Kang HK, van Veen HW, Fan T-P. Metabolites of ginsenosides as novel BCRP inhibitors. Biochem Biophys Res Commun 2006; 345: $1308-1314$

206 Kitagawa S, Takahashi T, Nabekura T, Tachikawa E, Hasegawa H. Inhibitory effects of ginsenosides and their hydrolyzed metabolites on daunorubicin transport in KB-C2 cells. Biol Pharm Bull 2007; 30: 1979-1981

207 Hao M, Zhao Y, Chen P, Huang H, Liu H, Jiang $H$, Zhang $R$, Wang $H$. Structure-activity relationship and substrate-dependent phenomena in effects of ginsenosides on activities of drug-metabolizing P450 enzymes. PLoS One 2008; 3: e2697

208 Pokharel YR, Kim ND, Han HK, Oh WK, Kang KW. Increased ubiquination of multidrug resistance 1 by ginsenoside Rd. Nutr Cancer 2010; 62: 252-259

209 Lee FC, Park JK, Ko JH, Lee JS, Kim KY, Kim EK. Efects of Panax ginseng extract on the benzo(a)pyrene metabolizing enzyme system. Drug Chem Toxicol 1987; 10: 227-236

210 Lee YJ, Pantuck CB, Pantuck EJ. Effect of ginseng on plasma levels of ethanol in the rat. Planta Med 1993; 59: 17-19

211 Gum SI, Jo SJ, Ahn SH, Kim SG, Kim JT, Shin HM, Cho MK. The potent protective effect of wild ginseng (Panax ginseng C.A. Meyer) against benzo[alpha]pyrene-induced toxicity through metabolic regulation of CYP1A1 and GSTs. J Ethnopharmacol 2007; 112: 568-576

212 Zhang R, Jie J, Zhou Y, Cao Z, Li W. Long-term effects of Panax ginseng on disposition of fexofenadine in rats in vivo. Am J Chin Med 2009; 37: 657-667

213 Zhu M, Chan KW, Ng LS, Chang Q Chang S, Li RC. Possible influences of ginseng on the pharmacokinetics and pharmacodynamics of warfarin in rats. J Pharm Pharmacol 1999; 51: 175-180

214 Yu C-T, Chen J, Teng XW, Tong V, Chang TKH. Lack of evidence for induction of CYP2B1, CYP3A23, and CYP1A2 gene expression by Panax ginseng and Panax quinquefolius extracts in adult rats and primary cultures of rat hepatocytes. Drug Metab Dispos 2005; 33: 19-22

215 Anderson GD, Rosito G, Mohustsy MA, Elmer GW. Drug interaction potential of soy extract and Panax ginseng. J Clin Pharmacol 2003; 43: 643-648

216 Jiang X, Williams KM, Liauw WS, Ammit AJ, Roufogalis BD, Duke CC, Day RO, McLachlan AJ. Effect of St John's wort and ginseng on the pharmacokinetics and pharmacodynamics of warfarin in healthy subjects. Br J Clin Pharmacol 2004; 57: 592-599

217 Lee LS, Wise SD, Chan C, Parsons TL, Flexner C, Lietman PS. Possible differential induction of phase 2 enzyme and antioxidant pathways by American ginseng, Panax quinquefolius. J Clin Pharmacol 2008; 48: 599-609

218 Lee S-H, Ahn Y-M, Ahn S-Y, Doo H-K, Lee B-C. Interaction between warfarin and Panax ginseng in ischemic stroke patients. J Altern Complement Med 2008; 14: 715-721

219 Andrade ASA, Hendrix C, Parsons TL, Caballero B, Yuan C-S, Flexner CW, Dobs AS, Brown TT. Pharmacokinetic and metabolic effects of American ginseng (Panax quinquefolius) in healthy volunteers receiving the HIV protease inhibitor indinavir. BMC Complement Altern Med 2008; 8: 50

220 Lee FC, Ko JH, Park JK, Lee JS. Effects of Panax ginseng on blood alcohol clearance in man. Clin Exp Pharmacol Physiol 1987; 14: 543-546

221 Yuan C-S, Wei G, Dey L, Karrison T, Nahlik L, Maleckar S, Kasza K, AngLee M, Moss J. American ginseng reduces warfarin's effect in healthy patients: a randomized, controlled trial. Ann Intern Med 2004; 141 : $23-27$ 
222 Jiang X, Blair EYL, McLachlan AJ. Investigation of the effects of herbal medicines on warfarin response in healthy subjects: a population pharmacokinetic-pharmacodynamic modeling approach. J Clin Pharmacol 2006; 46: 1370-1378

223 Janetzky K, Morreale AP. Probable interaction between warfarin and ginseng. Am J Health Syst Pharm 1997; 54: 692-693

224 Rosado MF. Thrombosis of a prosthetic aortic valve disclosing a hazardous interaction between warfarin and a commercial ginseng product. Cardiology 2003; 99: 111

225 Ames BN, Profet M, Gold LS. Dietary pesticides (99.99\% all natural). Proc Natl Acad Sci USA 1990; 87: 7777-7781

226 Murray M. Altered CYP expression and function in response to dietary factors: potential roles in disease pathogenesis. Curr Drug Metab 2006; 7: 67-81

227 Murray M. Mechanisms of inhibitory and regulatory effects of methylenedioxyphenyl compounds on cytochrome P450-dependent drug oxidation. Curr Drug Metab 2000; 1: 67-84

228 Hodgson E, Philpot RM. Interaction of methylenedioxyphenyl (1,3benzodioxole) compounds with enzymes and their effects on mammals. Drug Metab Rev 1974; 3: 231-301

229 Adams NH, Levi PE, Hodgson E. Regulation of cytochrome P-450 isozymes by methylenedioxyphenyl compounds. Chem Biol Interact 1993; 86: 255-274

230 Nakajima M, Suzuki M, Yamaji R, Takashina H, Shimada N, Yamazaki H, Yoko T. Isoform selective inhibition and inactivation of human cytochrome P450s by methylenedioxyphenyl compounds. Xenobiotica 1999; 29: 1191-1202

231 Chatterjee P, Franklin MR. Human cytochrome P450 inhibition and metabolic-intermediate complex formation by goldenseal extract and its methylenedioxyphenyl components. Drug Metab Dispos 2003; 31: 1391-1397

232 Gurley BJ, Swain A, Hubbard MA, Hartsfield F, Thaden J, Williams DK, Gentry WB, Tong Y. Supplementation with goldenseal (Hydrastis canadensis), but not kava kava (Piper methysticum), inhibits human CYP3A activity in vivo. Clin Pharmacol Ther 2008; 83: 61-69

233 Sandhu RS, Prescilla RP, Simonelli TM, Edwards DJ. Influence of goldenseal root on the pharmacokinetics of indinavir. J Clin Pharmacol 2003; 43: $1283-1288$

$234 \mathrm{Wu}$ X, Li Q Xin H, Yu A, Zhong M. Effects of berberine on the blood concentration of cyclosporine $A$ in renal transplanted recipients: clinical and pharmacokinetic study. Eur J Clin Pharmacol 2005; 61: 567-572

235 Xin H-W, Wu X-C, Li O Yu A-R, Zhong M-Y, Liu Y-Y. The effects of berberine on the pharmacokinetics of ciclosporin $A$ in healthy volunteers. Methods Find Exp Clin Pharmacol 2006; 28: 25-29

236 Pan GY, Wang GJ, Liu XD, Fawcett JP, Xie YY. The involvement of P-glycoprotein in berberine absorption. Pharmacol Toxicol 2002; 91: 193197

237 Tsai PL, Tsai TH. Hepatobiliary excretion of berberine. Drug Metab Dispos 2004; 32: 405-412

238 Shitan N, Tanaka M, Terai K, Ueda K, Yazaki K. Human MDR1 and MRP1 recognize berberine as their transport substrate. Biosci Biotechnol Biochem 2007; 71: 242-245

239 Nies AT, Herrmann E, Brom M, Keppler D. Vectorial transport of the plant alkaloid berberine by double-transfected cells expressing the human organic transporter 1 (OCT1, SLC22A1) and the efflux pump MDR1 P-glycoprotein (ABCB1). Naunyn Schmiedebergs Arch Pharmacol 2008; 376: 449-461

240 Qiu W, Jiang XH, Liu CX, Ju Y, Jin JX. Effect of berberine on the pharmacokinetics of substrates of CYP3A and P-gp. Phytother Res 2009; 23: 1553-1558

241 Gurley BJ, Swain A, Barone GW, Williams DK, Breen P, Yates CR, Stuart $L B$, Hubbard MA, Tong Y, Cheboyina S. Effect of goldenseal (Hydrastis canadensis) and kava kava (Piper methysticum) supplementation on digoxin pharmacokinetics in humans. Drug Metab Dispos 2007; 35 : 240-245

242 Gurley BJ. University of Arkansas for Medical Sciences, Little Rock. Personal communication. October 9, 2011

243 Gupta PK, Gurley BJ, Barone G, Hendrickson HP. Clinical pharmacokinetics and metabolism of berberine and hydrastine following an oral dose of goldenseal supplement. Planta Med 2010; 76: 546

244 Ulbricht C, Basch E, Boon H, Ernst E, Hammerness P, Sollars D, Tsourounis $C$. Safety review of kava (Piper methysticum) by the Natural Standard Research Collaboration. Expert Opin Drug Saf 2005; 4: 779-794
245 Côté CS, Kor C, Cohen J, Auclair K. Composition and biological activity of traditional and commercial kava extracts. Biochem Biophys Res Commun 2004; 322: 147-152

246 Unger M, Frank A. Simultaneous determination of the inhibitory potency of herbal extracts on the activity of six major cytochrome P450 enzymes using liquid chromatography/mass spectrometry and automated online extraction. Rapid Commun Mass Spectrom 2004; 18 : 2273-2281

247 Mathews JM, Etheridge AS, Black SR. Inhibition of human cytochrome P450 activities by kava extract and kava lactones. Drug Metab Dispos 2002; 30: 1153-1157

248 Unger M, Holzgrabe U, Jacobsen W, Cummins C, Benet LZ. Inhibition of cytochrome P450 3A4 by extracts and kavalactones of Piper methysticum (kava-kava). Planta Med 2002; 68: 1055-1058

249 Zou L, Henderson GL, Harkey MR, Sakai Y, Li A. Effects of kava (kava-kava, 'awa, yaqona, Piper methysticum) on c-DNA-expressed cytochrome P450 enzymes and human cryopreserved hepatocytes. Phytomedicine 2004; $11: 285-294$

250 Mathews JM, Etheridge AS, Valentine JL, Black SR, Coleman DP, Patel P, So J, Burka LT. Pharmacokinetics and disposition of the kavalactone kawain: interaction with kava extract and kavalactones in vivo and in vitro. Drug Metab Dispos 2005; 33: 1555-1563

251 Weiss J, Sauer A, Frank A, Unger M. Extracts and kavalactones of Piper methysticum G. Forst (kava-kava) inhibit P-glycoprotein in vitro. Drug Metab Dispos 2005; 33: 1580-1583

252 Raucy JL. Regulation of CYP3A4 expression in human hepatocytes by pharmaceuticals and natural products. Drug Metab Dispos 2003; 31: 533-539

253 Ma Y, Sachdeva K, Liu J, Ford M, Yang D, Khan IA, Chichester CO, Yan B. Desmethoxyyangonin and dihydromethysticin are two major pharmacological kavalactones with marked activity on the induction of CYP3A23. Drug Metab Dispos 2004; 32: 1317-1324

254 Yueh M-F, Kawahara M, Raucy J. High volume bioassays to assess CYP3A4-mediated drug interactions: induction and inhibition in a single cell line. Drug Metab Dispos 2005; 33: 38-48

255 Lim STS, Dragull K, Tang C-S, Bittenbender HC, Efird JT, Nerurkar PV. Effects of kava alkaloid, pipermethystine, and kavalactones on oxidative stress and cytochrome P450 in F-344 rats. Toxicol Sci 2007; 97: 214221

256 Clayton NP, Yoshizawa K, Kissling GE, Burka LT, Chan P-C, Nyska A. Immunohistochemical analysis of expressions of hepatic cytochrome P450 in F344 rats following oral treatment with kava extract. Exp Toxicol Path 2007; 58: 223-236

257 Yamazaki Y, Hashida H, Arita A, Hamaguchi K, Shimura F. High dose of commercial products of kava (Piper methysticum) markedly enhanced hepatic cytochrome P450 1A1 mRNA expression with liver enlargement in rats. Food Chem Toxicol 2008; 46: 3732-3738

258 Guo L, Li Q Xia Q Dial S, Chan P-C, Fu P. Analysis of gene expression changes of drug metabolizing enzymes in the livers of F344 rats following oral treatment with kava extract. Food Chem Toxicol 2009; 47: 433-442

259 Russman S, Barguil Y, Cabalion P, Rentsch K, Wenk M. Traditional aqueous kava extracts inhibit cytochrome P450 1A2 in humans: protective effect against environmental carcinogens? Clin Pharmacol Ther 2005; 77: 451-454

260 Srinivasan K. Black pepper and its pungent principle-piperine: a review of diverse physiological effects. Crit Rev Food Sci Nutr 2007; 47: 735-748

261 Atal CK, Zutshi U, Rao PG. Scientific evidence on the role of Ayurvedic herbals on bioavailability of drugs. J Ethnopharmacol 1981; 4: 229232

262 Friedman M, Levin CE, Lee S-U, Lee J-S, Ohnisi-Kameyama M, Kozukue $N$. Analysis by HPLC and LC/MS of pungent piperamides in commercial black, white, green, and red whole and ground peppercorns. J Agric Food Chem 2008; 56: 3028-3036

263 Dyer LA, Dodson CD, Richards J. Isolation, synthesis, and evolutionary ecology of Piper amides. In: Dyer LA, Palmer AN, editors. Piper. A model genus for studies of evolution, chemical ecology, and trophic interactions. Boston: Kluwer Academic Publishers; 2004: 117-139

264 Siddiqui BS, Gulzar T, Begum S, Afshan F, Sattar FA. Insecticidal amides from fruits of Piper nigrum Linn. Nat Prod Res 2005; 19: 143-150

265 Park I-K, Lee S-G, Shin S-C, Park J-D, Ahn Y-J. Larvicidal activity of isobutylamides identified in Piper nigrum fruits against three mosquito species. J Agric Food Chem 2002; 50: 1866-1870 
266 Atal CK, Dubey RK, Singh J. Biochemical basis of enhanced drug bioavailability by piperine: evidence that piperine is a potent inhibitor of drug metabolism. J Pharmacol Exp Ther 1985; 232: 258-262

267 Singh J, Dubey RK, Atal CK. Piperine-mediated inhibition of glucuronidation activity in isolated epithelial cells of the guinea-pig small intestine: evidence that piperine lowers the endogenous UDP-glucuronic acid content. J Pharmacol Exp Ther 1986; 236: 488-493

268 Dalvi RR, Dalvi PS. Differences in the effects of piperine and piperonyl butoxide on hepatic drug-metabolizing enzyme system in rats. Drug Chem Toxicol 1991; 14: 219-229

269 Reen RK, Singh J. In vitro and in vivo inhibition of pulmonary cytochrome $\mathrm{P} 450$ activities by piperine, a major ingredient of Piper species. Indian J Exp Biol 1991; 29: 568-573

270 Reen RK, Jamwal DS, Taneja SC, Koul JL, Dubey RK, Wiebel FJ, Singh J. Impairment of UDP-glucose dehydrogenase and glucuronidation activities in liver and small intestine of rat and guinea pig in vitro by piperine. Biochem Pharmacol 1993; 46: 229-238

271 Reen RK, Roesch SF, Kiefer F, Wiebel FJ, Singh J. Piperine impairs cytochrome P4501A1 activity by direct interaction with the enzyme and not by down regulation of CYP1A1 gene expression in the rat hepatoma 5 L cell line. Biochem Biophys Res Commun 1996; 218: 562-569

272 Reen RK, Wiebel FJ, Singh J. Piperine inhibits aflatoxin B1-induced cytotoxicity and genotoxicity in V79 Chinese hamster cells genetically engineered to express rat cytochrome P4502B1. J Ethnopharmacol 1997; 58: 165-173

273 Koul S, Koul JL, Taneja SC, Dhar KL, Jamwal DS, Singh K, Reen RK, Singh J. Structure-activity relationship of piperine and its synthetic analogues for their inhibitory potentials of rat hepatic microsomal constitutive and inducible cytochrome P450 activities. Bioorg Med Chem 2000; 8: 251-268

274 Bhardwaj RK, Glaeser H, Becquemont L, Klotz U, Gupta SK, Fromm MF. Piperine, a major constituent of black pepper, inhibits human P-glycoprotein and CYP3A4. J Pharmacol Exp Ther 2002; 302: 645-650

275 Subehan, Usia T, Kadota S, Tezuka Y. Mechanism-based inhibition of human liver microsomal cytochrome P450 2D6 (CYP2D6) by alkamides of Piper nigrum. Planta Med 2006; 72: 527-532

276 Suresh D, Srinivasan K. Influence of curcumin, capsaicin, and piperine on the rat liver drug-metabolizing enzyme system in vivo and in vitro. Can J Physiol Pharmacol 2006; 84: 1259-1265

277 Volak LP, Ghirmai S, Cashman JR, Court MH. Curcuminoids inhibit multiple human cytochromes P450, UDP-glucuronosyltransferase, and sulfotransferase enzymes, whereas piperine is a relatively selective CYP3A4 inhibitor. Drug Metab Dispos 2008; 36: 1594-1605

278 Han Y, Tan TMC, Lim L-Y. In vitro and in vivo evaluation of the effects of piperine on P-gp function and expression. Toxicol Appl Pharmacol 2008; 230: 283-289

279 Hiwale AR, Dhuley JN, Naik SR. Effect of co-administration of piperine on pharmacokinetics of beta-lactam antibiotics in rats. Indian J Exp Biol 2002; 40: 277-281

280 Aher S, Biradar S, Gopu CL, Paradkar A. Novel pepper extract for enhanced P-glycoprotein inhibition. J Pharm Pharmacol 2009; 61: 1179-1186

281 Okura T, Ibe M, Umegaki K, Shinozuka K, Yamada S. Effects of dietary ingredients on function and expression of P-glycoprotein in human intestinal epithelial cells. Biol Pharm Bull 2010; 33: 255-259

282 Najar IA, Sachin BS, Sharma SC, Satti NK, Suri KA, Johri RK. Modulation of P-glycoprotein ATPase activity by some phytoconstituents. Phytother Res 2010; 24: 454-458

283 Jin MJ, Han HK. Effect of piperine, a major component of black pepper, on the intestinal absorption of fexofenadine and its implication on food-drug interaction. J Food Sci 2010; 75: H93-H96

284 Selvendiran K, Thirunavukkarasu C, Singh JPV, Padmavathi R, Sakthisekaran $D$. Chemopreventative effect of piperine on mitochrondrial TCA cycle and phase-I and glutathione-metabolizing enzymes in benzo(a)pyrene induced lung carcinogenesis in Swiss albino mice. Mol Cell Biochem 2005; 271: 101-106

285 Dalvi RR, Dalvi PS. Comparison of the effects of piperine administered intragastrically and intraperitoneally on the liver and liver mixedfunction oxidases on rats. Drug Metabol Drug Interact 1991; 9: 23-30

286 Kang MH, Won SM, Park SS, Kim SG, Novak RF, Kim ND. Piperine effects on the expression of P4502E1, P4502B, and P4501A in rat. Xenobiotica 1994; 24: 1195-1204

287 Khajuria A, Thusu N, Zutshi U. Piperine modulates permeability characteristics of intestine by inducing alterations in membrane dynam- ics: influence on brush border membrane fluidity, ultrastructure and enzyme kinetics. Phytomedicine 2002; 9: 224-231

288 Zutshi RK, Singh R, Zutshi U, Johri RK, Atal CK. Influence of piperine on rifampicin blood levels in patients of pulmonary tuberculosis. JAPI 1985; 33: 223-224

289 Bano G, Amla V, Raina RK, Zutshi U, Chopra CL. The effect of piperine on pharmacokinetics of phenytoin in healthy volunteers. Planta Med 1987; 53: 568-569

290 Bano G, Raina RK, Zutshi U, Bedi KL, Johri RK, Sharma SC. Effect of piperine on bioavailability and pharmacokinetics of propranolol and theophylline in healthy volunteers. Eur J Clin Pharmacol 1991;41:615-617

291 Velpandian T, Jasuja R, Bhardwaj RK, Jaiseal J, Gupta SK. Piperine in food: interference in the pharmacokinetics of phenytoin. Eur J Drug Metab Pharmacokinet 2001; 26: 241-248

292 Pattanaik S, Hota D, Prabhakar S, Kharbanda P, Pandhi P. Effect of piperine on the steady-state pharmacokinetics of phenytoin in patients with epilepsy. Phytother Res 2006; 20: 683-686

293 Kasibhatta R, Naidu MUR. Influence of piperine on the pharmacokinetics of nevirapine under fasting conditions: a randomized, crossover, placebo-controlled study. Drugs R D 2007; 8: 383-391

294 Anand P, Kunnumakkara AB, Newman RA, Aggarwal BB. Bioavailability of curcumin: problems and promises. Mol Pharmacol 2007; 4: 807818

295 Bisht S, Maitra A. Systemic delivery of curcumin: 21st century solutions for an ancient conundrum. Curr Drug Discov Technol 2009; 6: 192-199

296 Shoba G, Joy D, Joseph T, Majeed M, Rajendran R, Srinivas PS. Influence of piperine on the pharmacokinetics of curcumin in animals and human volunteers. Planta Med 1998; 64: 353-356

297 Lambert JD, Hong J, Kim DH, Mishin VM, Yang CS. Piperine enhances the bioavailability of the tea polyphenol (-)-epigallocatechin-3-gallate in mice. J Nutr 2004; 134: 1948-1952

298 Panossian A, Wikman G. Pharmacology of Schisandra chinensis Bail.: an overview of Russian research and uses in medicine. J Ethnopharmacol 2008; 118: 183-212

299 Schisandra monograph. Natural Medicines Comprehensive Database. Available at: http://naturaldatabase.therapeuticresearch.com. Accessed October 26, 2010

300 Pan Q Tao W, Lu Q Hu X. Schisandrin B - a novel inhibitor of P-glycoprotein. Biochem Biophys Res Commun 2005; 335: 406-411

301 Pan Q Lu Q Zhang K, Hu X. Dibenzocyclooctadiene lingnans: a class of novel inhibitors of P-glycoprotein. Cancer Chemother Pharmacol 2006; 58: 99-106

302 Wan C-K, Zhu G-Y, Shen X-L, Chattopadhyay A, Dey S, Fong W-F. Gomi$\sin \mathrm{A}$ alters substrate interaction and reverses P-glycoprotein-mediated multidrug resistance in HepG2-DR cells. Biochem Pharmacol 2006; 72: 824-837

303 Yoo HH, Lee M, Lee MW, Lim SY, Shin J, Kim D-H. Effects of Schisandra lignans on P-glycoprotein-mediated efflux in human intestinal Caco2 cells. Planta Med 2007; 73: 444-450

304 Madgula VLM, Avula B, Choi YW, Pullela SV, Khan IA, Walker LA, Khan SI. Transport of Schisandra chinensis extract and its biologically-active constituents across Caco-2 cell monolayers - an in vitro model of intestinal transport. J Pharm Pharmacol 2008; 60: 363-370

305 Huang M, Jin J, Sun H, Liu GT. Reversal of P-glycoprotein-mediated multidrug resistance of cancer cells by five schizandrins isolated from the Chinese herb Fructus Schizandrae. Cancer Chemother Pharmacol 2008; 62: 1015-1026

306 Slaninová I, Brezinová L, Koubiková L, Slanina J. Dibenzocyclooctadiene lignans overcome drug resistance in lung cancer cells - study of structure-activity relationship. Toxicol In Vitro 2009; 23: 1047-1054

307 Iwata H, Tezuka Y, Usia T, Kadota S, Hiratsuka A, Watabe T. Inhibition of human liver microsomal CYP3A4 and CYP2D6 by extracts from 78 herbal medicines. J Tradit Med 2004; 21: 42-50

308 Iwata H, Tezuka Y, Kadota S, Hiratuska A, Watabe T. Identification and characterization of potent CYP3A4 inhibitors in Schisandra fruit extract. Drug Metab Dispos 2004; 32: 1351-1358

309 Makino T, Mizuno F, Mizukami H. Does a Kampo medicine containing Schisandra fruit affect pharmacokinetics of nifedipine like grapefruit juice? Biol Pharm Bull 2006; 29: 2065-2069

310 Mu Y, Zhang J, Zhang S, Zhou H-H, Toma D, Ren S, Huang L, Yaramus M, Baum A, Venkataramanan R, Xie W. Traditional Chinese medicines Wu Wei Zi (Schisandra chinensis Baill) and Gan Cao (Glycyrrhiza uralensis Fisch) activate pregnane $X$ receptor and increase warfarin clearance in rats. J Pharmacol Exp Ther 2006; 316: 1369-1377 
311 Lai L, Hao H, Wang Q, Zheng C, Zhou F, Liu Y, Wang Y, Yu G, Kang A, Peng $Y$, Wang $G$, Chen $X$. Effects of short-term and long-term pretreatment of Schisandra lignans on regulating hepatic and intestinal CYP3A in rats. Drug Metab Dispos 2009; 37: 2399-2407

312 Qin XL, Bi HC, Wang XD, Li JL, Wang Y, Xue XP, Chen X, Wang CX, Xu LJ, Wang YT, Huang $M$. Mechanistic understanding of the different effects of Wuzhi tablet (Schisandra sphenanthera extract) on the absorption and first-pass intestinal and hepatic metabolism of tacrolimus (FK506). Int J Pharm 2010; 389: 114-121

313 Lee SB, Kim CY, Lee HJ, Yun JH, Nho CW. Induction of the phase II detoxification enzyme NQO1 in hepatocarcinoma cells by lignans from the fruit of Schisandra chinensis through nuclear accumulation of Nrf2. Planta Med 2009; 75: 1314-1318

314 Jin J, Bi H, Hu J, Zhong G, Zhao L, Huang Z, Huang M. Enhancement of oral bioavailability of paclitaxel after oral administration of schisandrol B in rats. Biopharm Drug Dispos 2010; 31: 264-268

315 Liu K-T, Cresteil T, Columelli S, Lesca P. Pharmacological properties of dibenzo[a,c]cyclooctene derivatives isolated from Fructus Schizandrae chinensis. II. Induction of phenobarbital-like hepatic monooxygenases. Chem Biol Interact 1982; 39: 315-319

316 Salbe $A D$, Bjeldanes $L F$. The effects of dietary Brussels sprouts and Schizandra chinensis on the xenobiotic-metabolizing enzymes of the rat small intestine. Food Chem Toxicol 1985; 23: 57-65

317 Xin $H-W$, Wu X-C, Li Q Yu A-R, Zhu M, Shen Y, Su D, Xiong L. Effects of Schisandra sphenanthera extract on the pharmacokinetics of tacrolimus in healthy volunteers. Br J Clin Pharmacol 2007; 64: 469-475

318 Jiang W, Wang X, Xu X, Kong $L$. Effect of Schisandra sphenanthera extract on the concentration of tacrolimus in the blood of liver transplant patients. Int J Clin Pharmacol Ther 2010; 48: 224-229

319 Xin H-W, Wu X-C, Li Q Yu A-R, Xiong L. Effects of Schisandra sphenanthera extract on the pharmacokinetics of midazolam in healthy volunteers. Br J Clin Pharmacol 2009; 67: 541-546

320 Morazzoni P, Bombardelli E. Silybum marianum (Carduus marianus). Fitoterapia 1995; 64: 3-42

321 Kroll DJ, Shaw HS, Oberlies NH. Milk thistle nomenclature: why it matters in cancer research and pharmacokinetic studies. Integr Cancer Ther 2007; 6: 110-119

322 Saller R, Meier R, Brignoli R. The use of silymarin in the treatment of liver diseases. Drugs 2001; 61: 2035-2063

323 Rambaldi A, Jacobs BP, Iaquinto G, Gluud C. Milk thistle for alcoholic and/or hepatitis B or C liver diseases - a systematic Cochrane hepato-biliary group review with meta-analyses of randomized clinical trials. Am J Gastroenterol 2005; 100: 2583-2591

324 Tamayo C, Diamond S. Review of clinical trials evaluating safety and efficacy of milk thistle (Silybum marianum [L.] Gaertn.). Integr Cancer Ther 2007; 6: 146-157

325 Saller R, Brignoli R, Melzer J, Meier R. An updated systematic review with meta-analysis for the clinical evidence of silymarin. Forsch Komplementmed 2008; 15: 9-20

326 El-Kamary SS, Shardell MD, Abdel-Hamid M, Ismail S, El-Ateek M, Metwally M, Mikhail N, Hashem M, Mousa A, Aboul-Fotouh A, El-Kassas M, Esmat G, Strickland GT. A randomized controlled trial to assess the safety and efficacy of silymarin on symptoms, signs and biomarkers of acute hepatitis. Phytomedicine 2009; 16: 391-400

327 Lorenz D, Lücker PW, Mennicke WH, Wetzelsberger N. Pharmacokinetic studies with silymarin in human serum and bile. Methods Find Exp Clin Pharmacol 1984; 6: 655-661

328 Kim YC, Kim EJ, Lee ED, Kim JH, Jang SW, Kim YG, Kwon JW, Kim WB, Lee MG. Comparative bioavailability of silibinin in healthy male volunteers. Int J Clin Pharmacol Ther 2003; 41: 593-596

329 Schrieber SJ, Wen Z, Vourvahis M, Smith PC, Fried MW, Kashuba ADM, Hawke RL. The pharmacokinetics of silymarin is altered in patients with hepatitis $C$ virus and nonalcoholic fatty liver disease and correlates with plasma caspase-3/7 activity. Drug Metab Dispos 2008; 36: 1909-1916

330 Wen Z, Dumas TE, Schrieber SJ, Hawke RL, Fried MW, Smith PC. Pharmacokinetics and metabolic profile of free, conjugated, and total silymarin flavonolignans in human plasma after oral administration of milk thistle extract. Drug Metab Dispos 2008; 36: 65-72

331 Hawke RL, Schrieber SJ, Soule TA, Wen Z, Smith PC, Reddy R, Wahed AS, Belle SH, Afdhal NH, Navarro VJ, Berman J, Liu Q-Y, Doo E, Fried MW. Silymarin ascending multiple oral dosing phase I study in noncirrhotic patients with chronic hepatitis C. J Clin Pharmacol 2010; 50: 434-449
332 Miguez M-P, Anundi I, Sainz-Pardo LA, Lindros KO. Hepatoprotective mechanism of silymarin: no evidence for involvement of cytochrome P450 2E1. Chem Biol Interact 1994; 91: 51-63

333 Venkataramanan R, Ramachandran V, Komoroski BJ, Zhang S, Schiff PL, Strom SC. Milk thistle, a herbal supplement, decreases the activity of CYP3A4 and uridine diphosphoglucuronosyl transferase in human hepatocyte cultures. Drug Metab Dispos 2000; 28: 1270-1273

334 Beckmann-Knopp S, Rietbrock S, Weyhenmeyer R, Böcker RH, Beckurts $T$, Lang $W$, Hunz M, Fuhr $U$. Inhibitory effects of silibin on cytochrome P-450 enzymes in human liver microsomes. Pharmacol Toxicol 2000; 86: $250-256$

335 Zuber R, Modrianský M, Dvorák Z, Rohovský P, Ulrichová J, Simánek V, Anzenbacher $P$. Effect of silybin and its congeners on human liver microsomal cytochrome P450 activities. Phytother Res 2002; 16: 632638

336 Sridar C, Goosen TC, Kent UM, Williams JA, Hollenberg PF. Silybin inactivates cytochromes P450 3A4 and 2C9 and inhibits major hepatic glucuronosyl-transferases. Drug Metab Dispos 2004; 32: 587-594

337 Patel J, Buddha B, Dey S, Pal D, Mitra AK. In vitro interaction of the HIV protease inhibitor ritonavir with herbal constituents: changes in P-gp and CYP3A4 activity. Am J Ther 2004; 11: 262-277

338 Jancova P, Anzenbacherova E, Papouskova B, Lemr K, Luzna P, Veinlichova A, Anzenbacher P, Simanek V. Silybin is metabolized by cytochrome P450 2C8 in vitro. Drug Metab Dispos 2007; 35: 2035-2039

339 Doehmer J, Tewes B, Klein K-U, Gritzko K, Muschick H, Mengs U. Assessment of drug-drug interaction for silymarin. Toxicol In Vitro 2008; 22: 610-617

340 Brantley SJ, Oberlies NH, Kroll DJ, Paine MF. Two flavonolignans from milk thistle (Silybum marianum) inhibit CYP2C9-mediated warfarin metabolism at clinically achievable concentrations. J Pharmacol Exp Ther 2010; 332: 1081-1087

341 Maitrejean M, Comte G, Barron D, El Kirat K, Conseil G, Di Pietro A. The flavanolignan silybin and its hemisynthetic derivatives, a novel series of potential modulators of P-glycoprotein. Bioorg Med Chem Lett 2000; 10: 157-160

342 Zhang S, Morris ME. Effects of the flavonoids biochanin A, morin, phloretin, and silymarin on P-glycoprotein-mediated transport. J Pharmacol Exp Ther 2003; 304: 1258-1267

343 Zhang S, Morris ME. Effect of the flavonoids biochanin A and silymarin on the P-glycoprotein-mediated transport of digoxin and vinblastine in human intestinal Caco-2 cells. Pharm Res 2003; 20: 1184-1191

344 Chung SY, Sung MK, Kim NH, Jang JO, Go EJ, Lee HJ. Inhibition of P-glycoprotein by natural products in human breast cancer cells. Arch Pharm Res 2005; 28: 823-828

345 Morris ME, Zhang S. Flavonoid-drug interactions: effects of flavonoids on ABC transporters. Life Sci 2006; 78: 2116-2130

346 Miranda SR, Lee JK, Brouwer KLR, Wen Z, Smith PC, Hawke RL. Hepatic metabolism and biliary excretion of silymarin flavonolignans in isolated perfused rat livers: role of multidrug resistance-associated protein 2 (Abcc2). Drug Metab Dispos 2008; 36: 2219-2226

347 Deng JW, Shon J-H, Shin H-J, Park S-J, Yeo C-W, Zhou H-H, Song P-S, Shin $J-G$. Effect of silymarin supplement on the pharmacokinetics of rosuvastatin. Pharm Res 2008; 25: 1807-1814

348 Javed S, Kohli K, Ali M. Patented bioavailability enhancement techniques of silymarin. Recent Pat Drug Deliv Formul 2010; 4: 145-152

349 Barzaghi N, Crema F, Gatti G, Pifferi G, Perucca E. Pharmacokinetic studies on Idb 1016, a silybin-phosphatidylcholine complex, in normal human subjects. Eur J Drug Metab Pharmacokinet 1990; 15: 333-338

350 Gatti G, Perucca E. Plasma concentrations of free and conjugated silybin after oral intake of a silybin-phosphatidylcholine complex (silipide) in healthy volunteers. Int J Clin Pharmacol Ther 1994; 32: 614-617

351 Kidd P, Head K. A review of the bioavailability and clinical efficacy of milk thistle phytosome: a silybin-phosphatidylcholine complex (Siliphos $\left.^{\circledR}\right)$. Altern Med Rev 2005; 10: 193-203

352 Kidd PM. Bioavailability and activity of phytosome complexes from botanical polyphenols: the silymarin, curcumin, green tea, and grape seed extracts. Altern Med Rev 2009; 14: 226-246

353 Flaig TW, Gustafson DL, Su L-J, Zirrolli JA, Crighton F, Harrison GS, Pierson AS, Agarwal R, Glodé LM. A phase I and pharmacokinetic study of silybin-phytosome in prostate cancer patients. Invest New Drugs 2007; 25: 139-146 
354 Flaig TW, Glodé M, Gustafson D, van Bokhoven A, Tao Y, Wilson S, Su L-J, Li Y, Harrison G, Agarwal R, Crawford ED, Lucia MS, Pollak M. A study of high-dose oral silybin-phytosome followed by prostatectomy in patients with localized prostate cancer. Prostate 2010; 70: 848-855

355 Leber HW, Knauff S. Influence of silymarin on drug metabolizing enzymes in rat and man. Arzneimittelforschung 1976; 26: 1603-1605

356 Piscitelli SC, Formentini E, Burstein AH, Alfaro R, Jagannatha S, Falloon J. Effect of milk thistle on the pharmacokinetics of indinavir in healthy volunteers. Pharmacotherapy 2002; 22: 551-556

357 Mills E, Wilson K, Clarke M, Foster B, Walker S, Rachlis B, DeGroot N, Montori VM, Gold W, Phillips E, Myers S, Gallicano K. Milk thistle and indinavir: a randomized controlled pharmacokinetics study and meta analysis. Eur J Clin Pharmacol 2005; 61: 1-7

358 DiCenzo R, Shelton M, Jordan K, Koval C, Forrest A, Reichman R, Morse G. Coadministration of milk thistle and indinavir in healthy subjects. Pharmacotherapy 2003; 23: 866-870

359 van Erp NPH, Baker SD, Zhao M, Rudek MA, Guchelaar H-J, Nortier JWR, Sparreboom A, Gelderblom H. Effect of milk thistle (Silybum marianum) on the pharmacokinetics of irinotecan. Clin Cancer Res 2005; 11: 7800-7806

360 Fuhr U, Beckmann-Knopp S, Jetter A, Lück H, Mengs U. The effect of silymarin on oral nifedipine pharmacokinetics. Planta Med 2007; 73: 1429-1435

361 Rao BN, Srinivas M, Kumar YS, Rao YM. Effect of silymarin on the oral bioavailability of ranitidine in healthy human volunteers. Drug Metabol Drug Interact 2007; 22: 175-185

362 Han Y, Guo D, Chen Y, Tan Z-R, Zhou H-H. Effect of continuous silymarin administration on oral talinolol pharmacokinetics in healthy volunteers. Xenobiotica 2009; 39: 694-699

363 Rajnarayana K, Reddy MS, Vidyasagar J, Krishna DR. Study on the influence of silymarin pretreatment on metabolism and disposition of metronidazole. Arzneimittelforschung 2004; 54: 109-113

364 Han Y, Guo D, Chen Y, Chen Y, Tan Z-R, Zhou H-H. Effect of silymarin on the pharmacokinetics of losartan and its active metabolite E-3174 in healthy Chinese volunteers. Eur J Clin Pharmacol 2009; 65: 585-591

365 Ladas EJ, Kroll DJ, Oberlies NH, Cheng B, Ndao DH, Rheingold SR, Kelly $K M$. A randomized, controlled, double-blind, pilot study of milk thistle for the treatment of hepatotoxicity in childhood acute lymphoblastic leukemia (ALL). Cancer 2010; 116: 506-513

366 Hypericum Depression Trial Study Group. Effect of Hypericum perforatum (St John's wort) in major depressive disorder: a randomized controlled trial. JAMA 2002; 14: 1807-1814

367 Linde K, Berner MM, Kriston L. St. John's wort for major depression. Cochrane Database Syst Rev 2008; 4: CD000448

368 Beerhues L. Hyperforin. Phytochemistry 2006; 67: 2201-2207

369 Nahrstedt A, Butterweck V. Lessons learned from herbal medicinal products: the example of St John's wort. J Nat Prod 2010; 73: 10151021

370 Madabushi R, Frank B, Drewelow B, Derendorf H, Butterweck V. Hyperforin in St. John's wort interactions. Eur J Clin Pharmacol 2006; 62: 225-233

371 Whitten DL, Myers SP, Hawrelak JA, Wohlmuth $H$. The effect of St. John's wort extract on CYP3A: a systematic review of prospective clinical trials. Br J Clin Pharmacol 2006; 62: 512-526

372 Zhou S-F, Lai X. An update on clinical drug interactions with the herbal antidepressant St John's wort. Curr Drug Metab 2008; 9: 394-409

373 Kober M, Pohl K, Efferth T. Molecular mechanisms underlying St. John's wort drug interactions. Curr Drug Metab 2008; 9: 1027-1037

374 Borrelli F, Izzo AA. Herb-drug interactions with St John's wort (Hypericum perforatum): an update on clinical observations. AAPS J 2009; 11: $710-727$

375 Moore LB, Goodwin B, Jones SA, Wisely WB, Serabjit-Singh CJ, Willson TM, Collins JL, Kliewer SA. St John's wort induces hepatic drug metabolism through activation of the pregnane $\mathrm{X}$ receptor. Proc Natl Acad Sci USA 2000; 97: 7500-7502

376 Wentworth JM, Agostini M, Love J, Schwabe JW, Chatterjee VKK. St John's wort, a herbal antidepressant, activates the steroid $\mathrm{X}$ receptor. J Endocrinol 2000; 166: R11-R16

377 Watkins RE, Maglich JM, Moore LB, Wisely GB, Noble SM, Davis-Searlies $P R$, Lambert MH, Kliewer SA, Redinbo MR. 2.1 A crystal structure of human PXR in complex with the St John's wort compound hyperforin. Biochemistry 2003; 42: 1430-1438

378 Caccia S. Antidepressant-like components of Hypericum perforatum extracts: an overview of their pharmacokinetics and metabolism. Curr Drug Metab 2005; 6: 531-543
379 Wurglics M, Schubert-Zsilavecz M. Hypericum perforatum: a 'modern' herbal antidepressant, pharmacokinetics of active ingredients. Clin Pharmacokinet 2006; 45: 449-468

380 Wurglics M, Westerhoff K, Kaunzinger A, Wilke A, Baumeister A, Dressman J, Schubert-Zsilavecz M. Comparison of german St. John's wort products according to hyperforin and total hypericin content. J Am Pharm Assoc 2001; 41: 560-566

381 Gödtel-Armbrust U, Metzger A, Kroll U, Kelber O, Wojnowski L. Variability in PXR-mediated induction of CYP3A4 by commercial preparations and dry extracts of St. John's wort. Nauyn Schmiedebergs Arch Pharmacol 2007; 375: 377-382

382 Mai I, Bauer S, Perloff ES, Johne A, Uehleke B, Frank B, Budde K, Roots I. Hyperforin content determines the magnitude of the St John's wortcyclosporine drug interaction. Clin Pharmacol Ther 2004; 76: 330340

383 Arold G, Donath F, Maurer A, Diefenbach K, Bauer S, Henneicke-von Zepelin $H$, Friede $M$, Roots I. No relevant interaction with alprazolam, caffeine, tolbutamide, and digoxin by treatment with a low-hyperforin St. John's wort extract. Planta Med 2005; 71: 331-337

384 Mueller SC, Majcher-Peszynska J, Uehleke B, Klammt S, Mundkowski RG, Miekisch W, Sievers H, Bauer S, Frank B, Kundt G, Drewelow B. The extent of induction of CYP3A by St. John's wort varies among products and is linked to hyperforin dose. Eur J Clin Pharmacol 2006; 62: 29-36

385 Wang XD, Li JL, Su QB, Guan S, Chen J, Du J, He YW, Zeng J, Zhang JX, Chen $X$. Impact of the haplotypes of the human pregnane $X$ receptor gene on the basal and St John's wort-induced activity of cytochrome P450 3A4 enzyme. Br J Clin Pharmacol 2009; 67: 255-261

386 Imai H, Kotegawa T, Tsutsumi K, Morimoto T, Eshima N, Nakano S, Ohashi $K$. The recovery time-course of CYP3A after induction by St John's wort administration. Br J Clin Pharmacol 2008; 65: 701-707

387 Ajazuddin SS. Applications of novel drug delivery system for herbal formulations. Fitoterapia 2010; 81: 680-689

388 Gurley BJ. Emerging technologies for improving phytochemical bioavailability: benefits and risks. Clin Pharmacol Ther 2011; 89: 915919

389 Portoles A, Terleira A, Calvo A, Martinez I, Resplandy G. Effects of Hypericum perforatum on ivabradine pharmacokinetics in healthy volunteers: an open-label, pharmacokinetic interaction clinical trial. J Clin Pharmacol 2006; 46: 1188-1194

390 Dürr D, Stieger B, Kullak-Ublick GA, Rentsch KM, Steinert HC, Meier PJ, Fattinger K. St John's Wort induces intestinal P-glycoprotein/MDR1 and intestinal and hepatic CYP3A4. Clin Pharmacol Ther 2000; 68: 598-604

391 Johne A, Schmider J, Brockmoller J, Stadelmann AM, Stormer E, Bauer S, Scholler G, Langheinrich M, Roots I. Decreased plasma levels of amitriptyline and its metabolites on comedication with an extract from St. John's wort (Hypericum perforatum). J Clin Psychopharmacol 2002; 22: 46-54

392 Mueller SC, Uehleke B, Woehling H, Petzsch M, Majcher-Peszynska J, Hehl EM, Sievers H, Frank B, Riethling AK, Drewelow B. Effect of St John's wort dose and preparations on the pharmacokinetics of digoxin. Clin Pharmacol Ther 2004: 75: 546-557

393 Wang LS, Zhu B, El-Aty AM, Zhou G, Li Z, Wu J, Chen GL, Jie L, Tang ZR, Wang $A$. The influence of St. John's wort on CYP2C19 activity with respect to genotype. J Clin Pharmacol 2004; 44: 577-581

394 Rengelshausen J, Banfield M, Riedel K, Burhenne J, Weiss J, Thomsen T, Walter-Sack I, Haefeli W, Mikus G. Opposite effects of short-term and long-term St John's wort intake on voriconazole pharmacokinetics. Clin Pharmacol Ther 2005; 78: 25-33

395 Dresser GK, Schwarz UI, Wilkinson GR, Kim RB. Coordinate induction of both cytochrome P4503A and MDR1 by St John's wort in healthy subjects. Clin Pharmacol Ther 2005; 73: 41-50

396 Wang Z, Hamman MA, Huang SM, Lesko LJ, Hall SD. Effect of St John's wort on the pharmacokinetics of fexofenadine. Clin Pharmacol Ther 2002; 71: 414-420

397 Xie R, Tan LH, Polasek EC, Hong C, Teillol-Foo M, Gordi T, Sharma A, Nickens DJ, Arakawa T, Knuth DW. CYP3A and P-glycoprotein activity induction with St. John's wort in healthy volunteers from 6 ethnic populations. J Clin Pharmacol 2005; 45: 352-356

398 Sugimoto K, Ohmori M, Tsuruoka S, Nishiki K, Kawaguchi A, Harada K, Arakawa M, Sakamoto K, Masada M, Miyamori I. Different effects of St John's wort on the pharmacokinetics of simvastatin and pravastatin. Clin Pharmacol Ther 2001; 70: 518-524 
399 Andren L, Andreasson Å, Eggertsen R. Interaction between a commercially available St. John's wort product (Movina) and atorvastatin in patients with hypercholesterolemia. Eur J Clin Pharmacol 2007; 63: 913-916

400 Wang Z, Gorski C, Hamman MA, Huang S-M, Lesko LJ, Hall SD. The effects of St John's wort (Hypericum perforatum) on human cytochrome P450 activity. Clin Pharmacol Ther 2001; 70: 317-326

401 Markowitz JS, DeVane CL, Boulton DW, Carson SW, Nahas Z, Risch SC. Effect of St. John's wort (Hypericum perforatum) on cytochrome P-450 2D6 and 3A4 activity in healthy volunteers. Life Sci 2000; 66: 133-139

402 Markowitz JS, Donovan JL, DeVane CL, Taylor RM, Ruan Y, Wang JS, Chavin KD. Effect of St John's wort on drug metabolism by induction of cytochrome P450 3A4 enzyme. JAMA 2003; 290: 1500-1504

403 Kawaguchi A, Ohmori M, Tsuruoka S-I, Nishiki K, Harada K, Miyamori I, Yano R-I, Nakamura T, Masada M, Fujimura A. Drug interaction between St John's wort and quazepam. Br J Clin Pharmacol 2004; 58 : 403-410

404 de Maat MM, Hoetelmans RM, Math t RA, van Gorp EC, Meenhorst PL, Mulder JW, Beijnen JH. Drug interaction between St John's wort and nevirapine. AIDS 2001; 15: 420-421

405 Schwarz U, Hanso H, Dresser G, Kim R, Fromm M, Oertel R, Miehlke S, Kirch W. St. John's wort reduces oral bioavailability of talinolol in healthy volunteers. Clin Pharmacol Ther 2002; 71: P33

406 Tannergren C, Engman H, Knutson L, Hedeland M, Bondesson U, Lennernas $H$. St John's wort decreases the bioavailability of R- and S-verapamil through induction of the first-pass metabolism. Clin Pharmacol Ther 2004; 75: 298-309

407 Mathijssen RH, Verweij J, de Bruijn P, Loos WJ, Sparreboom A. Effects of St. John's wort on irinotecan metabolism. J Natl Cancer Inst 2002; 94: $1247-1249$

408 Frye RF, Fitzgerald SM, Lagattuta TF, Hruska MW, Egorin MJ. Effect of St John's wort on imatinib mesylate pharmacokinetics. Clin Pharmacol Ther 2004; 76: 323-329

409 Smith $P$. The influence of St. John's wort on the pharmacokinetics and protein binding of imatinib mesylate. Pharmacotherapy 2004; 24 : 1508-1514

410 Hall SD, Wang Z, Huang SM, Hamman MA, Vasavada N, Adigun AQ Hilligoss JK, Miller M, Gorski JC. The interaction between St John's wort and an oral contraceptive. Clin Pharmacol Ther 2003; 74: 525-535

411 Murphy PA, Kern SE, Stanczyk FZ, Westhoff CL. Interaction of St. John's Wort with oral contraceptives: effects on the pharmacokinetics of norethindrone and ethinyl estradiol, ovarian activity and breakthrough bleeding. Contraception 2005; 71: 402-408
412 Pfrunder A, Schiesser M, Gerber S, Haschke M, Bitzer J, Drewe J. Interaction of St John's wort with low-dose oral contraceptive therapy: a randomized controlled trial. Br J Clin Pharmacol 2003; 56: 683-690

413 Xu H, Williams KM, Liauw WS, Murray M, Day RO, McLachlan AJ. Effects of St John's wort and CYP2C9 genotype on the pharmacokinetics and pharmacodynamics of gliclazide. Br J Pharmacol 2008; 153: 15791586

414 Barone GW, Gurley BJ, Ketel BL, Lightfoot ML, Abul-Ezz SR. Drug interaction between St John's wort and cyclosporine. Ann Pharmacother 2000; 34: 1013-1016

415 Barone GW, Gurley BJ, Ketel BL, Abul-Ezz SR. Herbal dietary supplements: a source for drug interactions in transplant recipients. Transplantation 2001; 71: 239-241

416 Bauer S, Starmer E, Johne A, Krager H, Budde K, Neumayer H-H, Roots I, Mai I. Alterations in cyclosporin A pharmacokinetics and metabolism during treatment with St John's wort in renal transplant patients. $\mathrm{Br}$ J Clin Pharmacol 2003; 55: 203-211

417 Bolley R, Zulke C, Kammerl M, Fischereder M, Kramer BK. Tacrolimusinduced nephrotoxicity unmasked by induction of the CYP3A4 system with St John's wort. Transplantation 2002; 73: 1009

418 Hebert MF, Jeong MP, Yu-Luan C, Shahzad A, Anne ML. Effects of St. John's wort (Hypericum perforatum) on tacrolimus pharmacokinetics in healthy volunteers. J Clin Pharmacol 2004; 44: 89-94

419 Mai I, Budde K, Starmer E, Bauer S, Krager H, Roots I. Impact of St John's wort treatment on the pharmacokinetics of tacrolimus and mycophenolic acid in renal transplant patients. Nephrol Dial Transplant 2003; 18: 819-822

420 Eich-Hochli D, Oppliger R, Golay KP, Baumann P, Eap CB. Methadone maintenance treatment and St. John's wort - a case report. Pharmacopsychiatry 2003; 36: 35-37

421 Wang LS, Zhou G, Zhu B, Wu J, Wang JG, Abd El-Aty AM, Li T, Liu J, Yang TL, Wang D. St John's wort induces both cytochrome P450 3A4-catalyzed sulfoxidation and 2C19-dependent hydroxylation of omeprazole. Clin Pharmacol Ther 2004; 75: 191-197

422 Lundahl A, Hedeland M, Bondesson U, Knutson L, Lennernas $H$. The effect of St. John's wort on the pharmacokinetics, metabolism and biliary excretion of finasteride and its metabolites in healthy men. Eur J Pharm Sci 2009; 36: 433-443 